\title{
Protein Binding Effects of Dopamine Coated Titanium Dioxide Shell Nanoparticles
}

Ruben Omar Lastra ${ }^{\mathrm{a}}$, Tatjana Paunesku ${ }^{\mathrm{a}}$, Barite Gutama ${ }^{\mathrm{a}}$, Filiberto Reyes, Jr. ${ }^{\mathrm{a}}$, Josie François $^{\mathrm{a}}$, Shelby Martinez $^{\mathrm{a}}$, Lun Xin ${ }^{\mathrm{a}}$, Koshonna Brown ${ }^{\mathrm{a}}$, , Alia Zander ${ }^{\mathrm{a}}$, Sumita Raha ${ }^{\mathrm{a}}$, Miroslava Protic ${ }^{\mathrm{a}}$, Dhaval Nanavati ${ }^{\mathrm{b}}$, Yingtao $\mathrm{Bi}^{\mathrm{c}}$, Gayle E Woloschak ${ }^{\mathrm{a}}$

${ }^{a}$ Department of Radiation Oncology Feinberg School of Medicine, Northwestern University, Chicago, Illinois 60611, United States

${ }^{b}$ Chemistry of Life Processes Institute, Proteomics Core, Northwestern University, Evanston, Illinois 60208, United States

${ }^{c}$ Department of Biomedical Informatics, Feinberg School of Medicine, Northwestern University, Chicago, Illinois 60611, United States

Submitted: August 2, 2019

Accepted: September 17, 2019

Published: October 2, 2019

\section{Graphical Abstract}

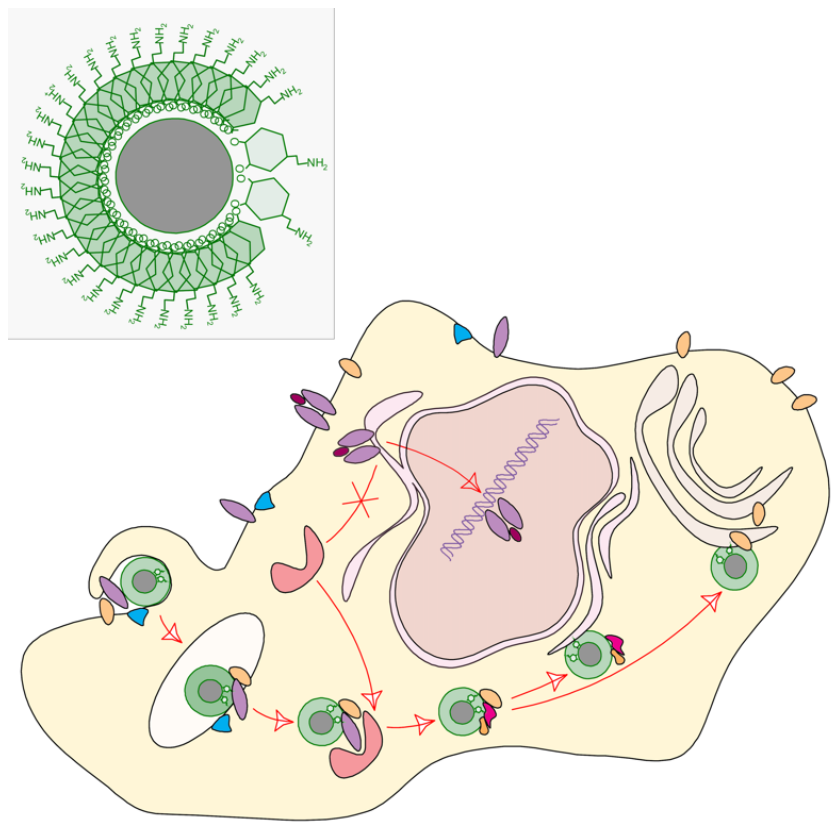

Metal oxide nanoparticles covered with dopamine (inset) enter cancer cells non-specifically (e.g. micropinocytosis), traverse intracellular vesicles and cytosol and interact with numerous proteins that change over time.

\section{Abstract}

Non-targeted nanoparticles are capable of entering cells, passing through different subcellular compartments and accumulating on their surface a protein corona that changes over time. In this study, we used metal oxide nanoparticles with iron-oxide core covered with titanium dioxide shell $\left(\mathrm{Fe}_{3} \mathrm{O}_{4} @ \mathrm{TiO}_{2}\right)$, with a single layer of covalently bound dopamine covering the nanoparticle surface. Mixing nanoparticles with cellular protein isolates showed that these nanoparticles can form complexes with numerous cellular proteins. The addition of non-toxic quantities of nanoparticles to HeLa cell culture resulted in their non-specific uptake and accumulation of protein corona on nanoparticle surface. TfRC, Hsp90 and PARP were followed as representative protein components of nanoparticle corona; each protein bound to nanoparticles with different affinity. The presence of nanoparticles in cells also mildly modulated gene expression on the level of mRNA. In conclusion, cells exposed to non-targeted nanoparticles show subtle but numerous changes that are consistent from one experiment to another.

\footnotetext{
\# To whom correspondence should be addressed. Email: g-woloschak@northwestern.edu
} 


\section{Keywords:}

Nanoparticles, Protein Corona, Cellular Pathways

\section{Purpose and Rationale}

Non-targeted nanoparticles are often taken up by cells non-specifically through all possible endocytic mechanisms. As they enter cells, reside in endosomes or get released into different subcellular compartments, nanoparticles encounter numerous proteins, interacting with them and their protein partners creating complexes of variable permanence and stability. Purpose of this study was to explore some of these interactions using dopamine coated $\mathrm{Fe}_{3} \mathrm{O}_{4} @ \mathrm{TiO}_{2}$ nanoparticles and document their effects on cells.

\section{Introduction}

Prediction of nanoparticle behavior is difficult even with the best characterized nanomaterials and experimental systems [1]. One of the wellknown, yet insufficiently understood reasons for this is that nanoparticles adsorb proteins in extracellular and intracellular milieus. These protein layers are referred to as the "protein corona" and an increasing body of literature emphasizes the importance of the protein corona for the subsequent fate of nanoparticles and their effects on cells and organisms [2, 3]. Research interest in nanoparticle protein coronas and their components is often focused on potential modification(s) of nanoparticle trafficking and function $[4,5]$. Studies exploring cellular responses to nanoparticles accumulating surface proteins, on the other hand, emphasize modulations of cellular processes such as changes of focal adhesion points[6] and cytoskeleton rearrangements [7], etc.

In the past, we have investigated interactions between nanoparticles and biological molecules, cells and subcellular compartments, dividing our attention between targeted [8-15] and non-targeted [16-19] nano-constructs prepared as iron oxide, titanium oxide or the combinations of these two materials. Others have also worked with different versions of titanium dioxide $\left(\mathrm{TiO}_{2}\right)$ based nanoparticles both in vitro and in vivo, focusing on primary and cancer cell lines and organisms such as drosophila, zebrafish, mutant and wild-type mice etc. [826]. The majority of these cell culture studies used nanoparticle concentrations in the toxic range, above 25 micrograms of $\mathrm{TiO}_{2}$ per $\mathrm{mL}$ depending on the biological system, size and crystalline form of $\mathrm{TiO}_{2}$ and other experimental conditions $[25,27]$.

In this work we use a non-targeted nano-construct - dopamine covered nanoparticles with an iron-oxide core and a titanium dioxide shell $\left(\mathrm{Fe}_{3} \mathrm{O}_{4} @ \mathrm{TiO}_{2}\right)$ and investigate interactions of this nanomaterial with the intracellular milieu of HeLa cells. The concentration of nanoparticles used $\left(20 \mu \mathrm{g} / \mathrm{mL}\right.$ of $\left.\mathrm{TiO}_{2}\right)$ is below cytotoxic levels and the period of nanoparticle incubation with cells in this study lasted as long as 24 hours with intermittent cell harvest for mRNA and protein isolation. Our interest was to evaluate protein corona of nanoparticles present in cells whose viability was not compromised - a situation similar to one that can be expected when exposure to nanoparticles is relatively low and not a part of a clinical treatment, for example. In our previous work we have explored nanoparticles functionalized by different targeting molecules $[8-10,14,15,28]$ attached via dopamine or dopac. While uptake of these nano-constructs was targeted and nanoparticles made to be toxic such as due to white light activation and DNA cleavage $[8,9]$; nanoparticles that failed functionalization with targeting moieties and carrying dopamine alone could be expected to enter any cell by non-specific endocytosis as we have shown in the past [19].

\section{Methods}

\section{Nanoparticle Preparation:}

All chemicals for the preparation of nanoparticles were purchased from Sigma (Sigma-Aldrich Corp., St. Louis, MO). Nanoparticles were synthesized as described before $[8,9,17$, 28] with $\mathrm{TiO}_{2}$ shell deposition by hydrolysis of $\mathrm{TiCl}_{4}$ under conditions that favor production of ultrasmall anatase $\mathrm{TiO}_{2}$ nanoparticles [29-31]. Synthesis of $\mathrm{TiO}_{2}$ shell was done in an ice cooled bath by adding $\mathrm{TiCl}_{4}$ chilled to $-20^{\circ} \mathrm{C}$ dropwise to a diluted colloidal suspension of $\mathrm{Fe}_{3} \mathrm{O}_{4}$ nanoparticles. Synthesis of iron oxide nanoparticles was described elsewhere $[8,9,17$, 28]; briefly, a combination of $\mathrm{FeCl}_{2}$ and $\mathrm{FeCl}_{3}$ in $24 \mathrm{mM}$ citric acid was steered for $3 \mathrm{hr}$ at room temperature and aged in static air at $70^{\circ} \mathrm{C}$ 
for 24 hours, forming the $\mathrm{Fe}_{3} \mathrm{O}_{4}$ core nanoparticles 1.5 to $3 \mathrm{~nm}$ in size. These particles were covered with a $\mathrm{TiO}_{2}$ shell layer, for a final nanoparticle size between 10-20 nm (Supplemental Figure 1). In the course of the synthesis a color change of nanoparticle suspension was noted from rust (pure iron oxide nanoparticle solution) to pale yellow (core-shell nanoparticle solution). Nanoparticle sizing was done by cryo transmission electron microscopy on a JEOL $1230120 \mathrm{kV}$ Transmission Electron Microscope at the Northwestern University Biological Imaging Facility (BIF) (Supplemental Figure 1). Final $\mathrm{TiO}_{2}$ concentration in colloidal nanoparticle suspension was $200 \mu \mathrm{g} / \mathrm{mL}$ as measured at the Northwestern University Quantitative Bio-element Imaging Center (QBIC) using an X Series II Inductively Coupled PlasmaMass Spectrometer (Thermo Fisher Scientific, West Palm Beach, FL). A series of standards ranging from $0 \mathrm{ppb}$ to $50 \mathrm{ppb}$ titanium was used. All standards and samples were spiked with $3 \mathrm{ppb}$ of indium as an internal control. Using the approach explained before $[8,9,17]$ we calculated that this corresponds to an approximate $180 \mathrm{nM}$ nanoparticle concentration (for a nanoparticle size of $10 \mathrm{~nm}$ ), with an approximate $300 \mu \mathrm{M}$ concentration of surface binding sites. The complete $\mathrm{TiO}_{2}$ shell surface was covered with dopamine by dissolving $21 \mathrm{mg}$ of powdered dopamine in $55 \mathrm{~mL}$ of as-prepared nanoparticle colloid ( $\mathrm{pH} \sim 1)$. The final concentration of dopamine was $2 \mathrm{mM}$, several fold greater than the molarity of available nanoparticle surface sites. The newly coated nanoparticles were dialyzed in $10 \mathrm{mM}$ sodium phosphate and $40 \mathrm{mM}$ sodium chloride buffer $\mathrm{pH} 4.5$ in order to stabilize the covalent bond between dopamine and $\mathrm{TiO}_{2}$ surface and remove excess dopamine. Use of dialysis tubing (Slide-ALyzer $^{\mathrm{TM}}$ Dialysis Cassettes, Thermo Fisher Scientific, West Palm Beach, FL) with $2 \mathrm{KDal}$ pores allowed removal of unbound dopamine from the nanoparticle mixture. If any of the $\mathrm{TiO}_{2}$ molecules on nanoparticle surface were free at the time of dialysis, they could have bound to phosphates through hydrogen bonds [32]; more importantly, dialysis provided chloride and phosphate ions that could neutralize $\mathrm{NH}_{3}{ }^{+}$group of dopamine and change polarity of nanoparticles. In the course of dialysis nanoparticle colloidal mixture changed appearance from a transparent pale yellow liquid to a partially opaque light brown solution. This red shift in nanoparticle absorption is characteristic for covalently modified $\mathrm{TiO}_{2}$ nanoparticle surface [31] (Supplemental Figure 2). Nanoparticles remained stable in solution for more than 6 months. Nanoparticles were further diluted in $10 \mathrm{mM}$ sodium chloride and evaluated by Zetasizer Nano (Malvern, Worcestershire, United Kingdom); zeta potential of dopaminecoated and dialyzed nanoparticles was $-27 \mathrm{mV}$ and their hydrodynamic diameter about $90 \mathrm{~nm}$, with the formation of aggregates with a hydrodynamic diameter of about $900 \mathrm{~nm}$ (Supplemental Figure 3). This work was performed at the Northwestern University's Analytical BioNanoTechnology Equipment Core of the Simpson Querrey Institute.

\section{Cell Culture and Nanoparticle Treatments:}

Cervical cancer cell line HeLa (CCL-2 ATCC, Manassas, Virginia) was grown in DMEM supplemented with $10 \%$ fetal bovine serum and $1 \%$ penicillin/streptomycin (all obtained from Corning Cellgro, Fisher Scientific) at $37{ }^{\circ} \mathrm{C}$ and $5 \% \mathrm{CO}_{2}$. Intermittent mycoplasma testing consisted of optical fluorescence imaging of cells grown on microscope slides and stained with in phosphate buffered saline (PBS) with $0.01 \mathrm{mg} / \mathrm{mL}$ of 4 ',6-Diamidino-2-Phenylindole, Dihydrochloride (DAPI) (Sigma-Aldrich Corp., St. Louis, MO), similar to work of others [33].

Cells were counted before plating using a BioRad TC20 (Bio-Rad, Hercules, CA) automated cell counter. Either $5 \times 10^{5}$ or $10^{6}$ cells were plated per T25 flask 16-18h prior to treatment; these cell densities corresponded roughly to $40 \%$ and $80 \%$ confluent cells monolayers 16-18 hours later when nanoparticle treatments had begun.

Dialyzed dopamine coated nanoparticles were added as $1 / 10$ th of the volume to $5 \mathrm{~mL}$ of complete media per T25 flask. The final concentration of $\mathrm{TiO}_{2}$ in media was $20 \mu \mathrm{g} / \mathrm{mL}$ (or, in standard T25 flasks, $4 \mu \mathrm{g} / \mathrm{cm} 2$ ). Each nanoparticle-exposed cell flask was paired with an untreated control flask in all protein and mRNA isolations and assays.

Staurosporine treatment:

HeLa cells were seeded to achieve $40 \%$ confluence in 16-18 hours. Dopamine covered 
$\mathrm{Fe}_{3} \mathrm{O}_{4} @ \mathrm{TiO}_{2}$ nanoparticles were given to selected flasks of cells for 2 hours followed by treatment with staurosporine $(1 \mu \mathrm{M}, 0.1 \mu \mathrm{M}$ or $0.01 \mu \mathrm{M}$ ) for 4 hours. Staurosporine (Enzo Scientific, Farmingdale, NY) was dissolved in dimethyl sulfoxide (DMSO) at $1 \mathrm{mM}$ concentration. DMSO alone served as a negative control.

\section{Protein Extracts:}

HeLa cells were plated in T-25 flasks at densities of $5 \times 10^{5}$ or $1 \times 10^{6}$ at 16 hours before the beginning of the experiment. The cells were then washed three times with PBS and resuspended in $100 \mu \mathrm{L}$ of RIPA buffer (Thermo Scientific 89900) with Protease inhibitors (diluted from 1x to 100x) (Calbiochem 539131). Each flask was scraped and the liquid (mixture of cells and buffer) was removed from the flask and transferred to a new microcentrifuge tube. Samples were then rocked at medium speed in $4{ }^{\circ} \mathrm{C}$ for 15 minutes. Next, the tubes were centrifuged in $4{ }^{\circ} \mathrm{C}$ for $15 \mathrm{~min}$ at maximum speed, the supernatant was transferred to a new microfuge tube and the protein concentration was calculated using Bradford reagent (Bio-Rad 50000205) and the NanoDrop-3000 (NanoDrop, Wilmington, DE) and BSA $(2000 \mu \mathrm{g} / \mathrm{mL})$ (BioRad 500-0206) was used as a standard.

Isolation and Partial Characterization of Proteins Adhering to Nanoparticles:

HeLa cell nuclear and cytoplasmic lysates were prepared using standard procedures. In short, cells washed in PBS were resuspended in $5 \mathrm{~V}$ (compared to cell $\mathrm{V}$ ) of buffer A (10 mM Tris $10 \mathrm{mM} \mathrm{KCl}, 1.5 \mathrm{MgCl}_{2}, \mathrm{pH} \sim 7.9,0.5 \mathrm{mM}$ DTT), spun for 5 minutes at 3000 rpm, resuspended in $2 \mathrm{~V}$ of buffer A for 10 minutes on ice and broken into cytosolic fraction and nuclei by homogenization. Nuclei were resuspended in $0.5 \mathrm{~V}$ buffer C (20 mM Tris pH7.9, $0.02 \mathrm{M} \mathrm{KCl}$, $1.5 \mathrm{mM} \mathrm{MgCl}_{2}, 25 \%$ glycerol, $0.5 \mathrm{mM}$ DTT and $0.2 \mathrm{mM}$ PMSF) and mixed gently with equal $\mathrm{V}$ of buffer $\mathrm{D}(20 \mathrm{mM}$ Tris $\mathrm{pH} 7.9,1.2 \mathrm{M}$ $\mathrm{KCl}, 1.5 \mathrm{mM} \mathrm{MgCl} 2,25 \%$ glycerol, $0.5 \mathrm{mM}$ DTT and $0.2 \mathrm{mM}$ PMSF) and steered for 30 minutes. Both fractions were centrifuged at $13,000 \mathrm{~g}$ in in a tabletop centrifuge (BeckmanCoulter, Indianapolis, IN) for 30 minutes before incubation of supernatant with nanoparticles. Protein extracts $(200 \mu \mathrm{g}$ of each) were incubated with $100 \mu \mathrm{L}$ nanoparticles for 16 hours on a rocking platform at $4{ }^{\circ} \mathrm{C}$. Protein and na- noparticle pellets were "washed" by resuspending-centrifugation in $2 \mathrm{x}$ Laemmli Sample Buffer three times. Finally, beta-mercaptoethanol (Sigma-Aldrich, St Louis, MO) was added to the mixtures and they were heated at $95{ }^{\circ} \mathrm{C}$ for 5 minutes to denature and separate the more resistant protein corona from the nanoparticles. Samples were briefly spun to remove residual nanoparticles and the supernatants were loaded onto gradient (4-20\%) SDS-PAGE gels. Gels were run and stained with Comassie Blue (BioRad, Hercules, CA). Nuclear and cytoplasmic extracts (Supplemental Figure 4) were loaded on the gel as controls. Areas with protein bands enriched in lanes where proteins were stripped from nanoparticles were selected for further work. Pieces of gel containing multiple bands of proteins were excised and submitted for processing to the NU Protein core facility. Briefly, protein was digested with $200 \mathrm{ng}$ of sequencing grade trypsin (Sigma-Aldrich Corp., St. Louis, $\mathrm{MO})$ at $37^{\circ} \mathrm{C}$ for $18 \mathrm{hr}$. The digested protein preparation was dried, resuspended in $500 \mu \mathrm{L}$ of $5 \%$ acetonitrile, $0.1 \%$ formic acid (SigmaAldrich Corp., St. Louis, MO) and desalted using $\mathrm{C} 18$ spin columns (Thermo Fisher Scientific, West Palm Beach, FL). The desalted peptides were loaded onto a $10 \mathrm{~cm}$ long, $75 \mu \mathrm{M}$ reversed phase capillary column (ProteoPep ${ }^{\mathrm{TM}}$ II C18, $300 \AA, 5 \mu \mathrm{m}$ size, New Objective, Woburn, MA) and separated with a 100 min gradient from $5 \%$ acetonitrile to $100 \%$ acetonitrile on a Proxeon Easy n-LC II (Thermo Fisher Scientific, West Palm Beach, FL). The peptides were directly eluted into an LTQ Orbitrap Velos mass spectrometer (Thermo Fisher Scientific, Waltham, MA USA) with electrospray ionization at $350 \mathrm{~nL} / \mathrm{min}$ flow rate. The peptide MS data were analyzed using Proteome Discoverer (version 1.3, Thermo Fisher Scientific) and searched using an in-house MASCOT server against the Swiss-Prot database (version 2011_12). The species filters for database search for samples was Homo sapiens.

Protein Isolation from Nanoparticle Treated Cells and Isolation of Proteins Adhering to Nanoparticles:

After nanoparticle treatments of 0, 1, 2, 4, 6 or 24 hours, nanoparticle treated and control cells were washed three times with PBS (Thermo Fisher Scientific, West Palm Beach, FL) and collected in $100 \mu \mathrm{L}$ of RIPA buffer (Thermo Fisher Scientific, West Palm Beach, 
FL) with Protease inhibitors (Calbiochem). Cells were collected by scraping and rocked at $4{ }^{\circ} \mathrm{C}$ for 15 minutes. According to the standard procedure, cell lysates were centrifuged at $13,000 \mathrm{~g}$ for 15 minutes at $4^{\circ} \mathrm{C}$ in a tabletop centrifuge (Beckman-Coulter, Indianapolis, IN) to separate proteins from cell debris and the supernatant was transferred to a new microfuge tube. The protein concentration was calculated using Bradford assay with BSA as a standard using NanoDrop 2000 (Thermo Fisher Scientific, Waltham, MA USA); all Bradford assay chemicals came from Bio-Rad (Hercules, CA).

For isolation of proteins forming corona on nanoparticles initial steps for protein isolation were done as above. After cell lysis however, the supernatant was removed and the pellet resuspended in $200 \mu \mathrm{L} 2 \mathrm{X}$ Laemmli Sample Buffer (Bio-Rad, Hercules, CA). The resuspended pellet was then centrifuged for $10 \mathrm{~min}$ at $10,000 \mathrm{~g}$, the supernatant was removed and saved ("the first wash") and this was repeated two more times ("second and third washes"). Finally, the pellet was resuspended in $80 \mu \mathrm{L}$ of Laemmli Sample Buffer, boiled at $95^{\circ} \mathrm{C}$ for 10 minutes, spun to remove the residual nanoparticle aggregates and loaded on a gel.

\section{Western Blots:}

Immunoblots were done with protein extracts adjusted to same concentration by diluting with PBS and mixing 1:1 with 4X Laemmli Sample Buffer (Bio-Rad 161-0747). Samples were then separated with a Bio-Rad gradient SDS Gel (420\%) (Bio-Rad 456-8093). Afterwards, the samples were transferred to a nitrocellulose membrane (Bio-Rad 162-0145) that was blocked by $5 \%$ skimmed milk (Bio-Rad 170 6404) in $1 \times$ TBS-T (Tris-NaCl-Tween 20) for 2 hours and then incubated overnight with primary antibodies: Hsp90 (Ab13495 1:10,000), , PARP (Ab32138, 1:5:000), and Apoptosis Western Blot Cocktail (pro/p17-caspase 3, cleaved-PARP, muscle actin) (ab136812, $1: 250)$. The membrane was washed three times with $1 \times$ TBS-T and then probed with secondary antibodies $(1: 10,000)$ (Cell Signaling 7074S and 7076S) tagged with horseradish peroxidase (HRP) and incubated for $1 \mathrm{~h}$ at room temperature. The membrane was overlaid with Clarity Western ECL Substrate (Bio-Rad 1705061) according to the manufacturer's instructions, and the blots were developed.

\section{RNA Isolation:}

HeLa cells were plated and treated with nanoparticles as above; harvest was done at $2 \mathrm{~h}$ and 4h timepoints. Total RNA was isolated using the PureLink RNA Mini kit (12183020 Thermo Fisher Scientific, West Palm Beach, FL). RNA quantity was assessed with a NanoDrop 2000 Spectrophotometer (Thermo Fisher Scientific, Wilmington, Delaware).

RNA was submitted to NU Center for Genetic Medicine core facility for processing. RNA quality evaluation was done using Agilent 2100 bioanalyzer (Agilent, Santa Clara, CA); RIN of ten was obtained for all samples and $\mathrm{Hu}-$ manHT12-v4 Illumina arrays (Illumina Inc., San Diego, CA) were used for gene expression evaluation. Four sets of biological replicates were prepared and tested, as well as one technical replicate. All of the samples met the Illumina quality checks. Initial data quality checks were performed using Bioconductor Lumi package [39]. Raw array data was submitted to Gene Expression Omnibus (GEO) database (www.ncbi.nlm.nih.gov/geo/) under accession number GSE88786. Subsequent analysis included ComBat [40] analysis in order to remove batch effects; final data output was obtained using Limma model [41] with cutoff q-value = 0.1 .

\section{Quantitative Real-time Polymerase Chain} Reaction (QRT-PCR):

For each sample $1 \mu \mathrm{g}$ of total RNA was reverse transcribed using the High-Capacity RNA-tocDNA $^{\text {TM }}$ Kit (4387406 Thermo Fisher Scientific, West Palm Beach, FL).PCR was done using Power SYBR Green PCR Master Mix (4367659 Thermo Fisher Scientific, West Palm Beach, FL) and $250 \mathrm{nM}$ of specific primers in a total volume of $25 \mu \mathrm{L}$ in a 7300 Real Time PCR system (Applied Biosystems, Foster City, CA) Samples were tested at least in triplicate and up to six times on the same plate (samples values closest to the mean were used for analysis) and negative control PCR amplification, with water instead of cDNA, was performed for every plate and every primer pair. After incubation for two minutes at $50{ }^{\circ} \mathrm{C}$ and a denaturation step of 10 minutes at $95^{\circ} \mathrm{C}$, samples were subjected to 40 cycles $\left(30\right.$ seconds at $95^{\circ} \mathrm{C}, 30$ seconds at $60^{\circ} \mathrm{C}$, 30 seconds at $72{ }^{\circ} \mathrm{C}$ ), following by the acquisition of the melting curve. One reference gene was used: beta-actin. Predesigned primers were 
purchased from Integrated DNA Technologies, Inc. (IDT, Coralville, Iowa). Primer pairs specific for transferrin receptor: Hs.PT.58.22906586, Hsp90: Hs.PT.58.38593314.g; $\quad$ GPER: Hs.PT.58.1412417; MAP3K14: Hs.PT.58.14658535; Hs.PT.58.18791272.g; $\quad$ ID2: Hs.PT.58.38958353; ID3: Hs.PT.58.27440053.g; Dusp2: Hs.PT.58.39972211.g; $\quad$ CLDN15: Hs.PT.58.20001672; SMUG: Hs.PT.58.27762894; $\quad$ FZD9: Hs.PT.58.4929232.g were obtained. Primer pair for PARP1 was obtained from Sigma (SigmaAldrich Corp., St. Louis, MO); it included sense 5'CTTGGACCGAGTAGCTGATGG (positions 1008 to 1028 in reference sequence NM_001618.3) and antisense (pos. 1100 to 1120 5'AGTGCAGTAATAGGCATCGCT primers.

$\mathrm{Ct}$ for each one of the three biological replicate PCR reactions (each with $>=3$ technical replicates) was calculated from technical replicates; these were selected to fulfill the criteria for low variance (less than $0.5 \mathrm{Ct}$ values from each other) and averaged. Standard deviation for average $\Delta \Delta \mathrm{Ct}$ values from three biological replicates was calculated for each mRNA and timepoint. Statistical significance was calculated by doing an f-test and determining if the samples had similar variance or not, followed by the appropriate t-test (two-sample assuming equal variances or two-sample assuming unequal variances) to determine statistical significance.

\section{Bioinformatics analysis:}

Pathway analysis for gene IDs for proteins attached to nanoparticles as well as mRNAs was done using DAVID Bioinformatics Resources https://david.ncifcrf.gov/home.jsp sponsored by the NIAID, NIH $[31,32]$.

\section{Results}

Nanoparticles of the final size between 10-20 $\mathrm{nm}$ were made from $2 \mathrm{~nm} \mathrm{Fe} \mathrm{O}_{4}$ cores overlaid with a $\mathrm{TiO}_{2}$ shell (Supplemental Figure 1) as described before $[8,9,17]$. Final $\mathrm{TiO}_{2}$ concentration in this colloidal nanoparticle suspension was $200 \mu \mathrm{g} / \mathrm{mL}$. Nanoparticle surface was fully covered with dopamine and the nanoparticles dialyzed in $10 \mathrm{mM}$ sodium phosphate $-40 \mathrm{mM}$ sodium chloride $\mathrm{pH} \sim 4.5$. Initially, nanoparticles were mixed with HeLa protein cell extracts for 16 hours at $4{ }^{\circ} \mathrm{C}$ and precipitated in order to maximize interactions between nanoparticles, proteins and protein complexes similar to immunoprecipitation approaches. Pellets consisting of nanoparticles and proteins were washed several times in protein extraction buffer; proteins that remained attached to nanoparticles after two such washes were eluted by a final wash in $2 \times$ Laemmli Buffer heated to $95{ }^{\circ} \mathrm{C}$ for 5 minutes. Eluted proteins were separated by electrophoresis (Supplemental Figure 4). Because of the high number of proteins eluted from nanoparticles, only some portions of the polyacrylamide gel were processed by mass spectrometry (Supplemental Figure 4). 252 proteins identified by this approach are listed in Supplemental Table 1. Based on bioinformatics analysis - these proteins participate in $60 \mathrm{DA}$ VID annotation clusters with enrichment scores above one and up to 16 (for example, nucleotide binding sub-cluster included 114 proteins).

Three proteins were selected for further study - a cell membrane protein - transferrin receptor 1 (TfRC) which is in charge of importing transferrin, a metal binding glycoprotein, into cell [34]; a cytosolic protein - heat shock protein 90 (Hsp90) which is involved in the folding and conformational regulation of numerous client proteins and has been implicated in different cellular signaling networks (e.g., steroid hormone receptors, transcription factors and protein kinases)[35]; and a nuclear protein poly(ADP-ribose) polymerase (PARP) which is involved in repair of single-stranded DNA breaks (SSBs) [36], regulation of chromatin structure, DNA metabolism and gene expression [37]. Paired flasks of HeLa cells seeded to reach 40 or $80 \%$ confluency overnight were treated with nanoparticles diluted to $20 \mu \mathrm{g} / \mathrm{mL}$ in complete medium. From the initial moment of nanoparticle treatment up to 24 hours later, pairs of nanoparticle treated cells and controls were harvested and total cellular proteins isolated using RIPA buffer and a standard processing procedure (see Methods).Previous work with non-targeted nanoparticles by our group [19] as well as others [7] has shown that non-targeted nanoparticles enter cells by every possible endocytic mechanism and that nanoparticle accumulation in cells reaches a plateau within 2 hours after treatment. Cells treated with nanoparticles and the control cells were 
harvested for protein extraction immediately after nanoparticle treatment ( $0 \mathrm{~h}$ timepoint) and at 1, 2, 4, 6 and 24 hours after nanoparticle treatment. Because standard protein isolation procedure includes centrifugation steps, nanoparticles present in protein extracts were precipitated and discarded in the course of the protein isolation procedure. However, because protein corona remained attached to the nanoparticles, protein supernatants from nanoparticle treated cells showed depletion of these proteins as well as proteins with decreased expression. Figure 1 shows representative Western blots for the TfRC, Hsp90 and PARP. Equal protein concentrations were loaded in each lane and Western blots for actin for each membrane were done in parallel with Western blots for protein of interest. Although actin binds to nanoparticles, we found its abundance in Western blots unchanged from lane to lane when equal amounts of proteins were loaded. We reasoned that it is possible either that actin binding to nanoparticle was less abundant when nanoparticles interacted with whole cells rather than cell lysates or that this protein has such high abundance in cells that it is difficult to deplete it. Of the three proteins tested, the quantity of Hsp90 (as much as $1 \%$ of all cell protein) appeared unchanged, similar to actin. Two other test proteins, however, showed decrease in nanoparticle treated samples. A decrease of TfRC was the most notable between 6 hours and 24 hours post-treatment. Depletion of PARP was the most pronounced and of greatest duration - no PARP was observed in any of the nanoparticle treated samples between 1-24 $\mathrm{h}$ after nanoparticle treatment.
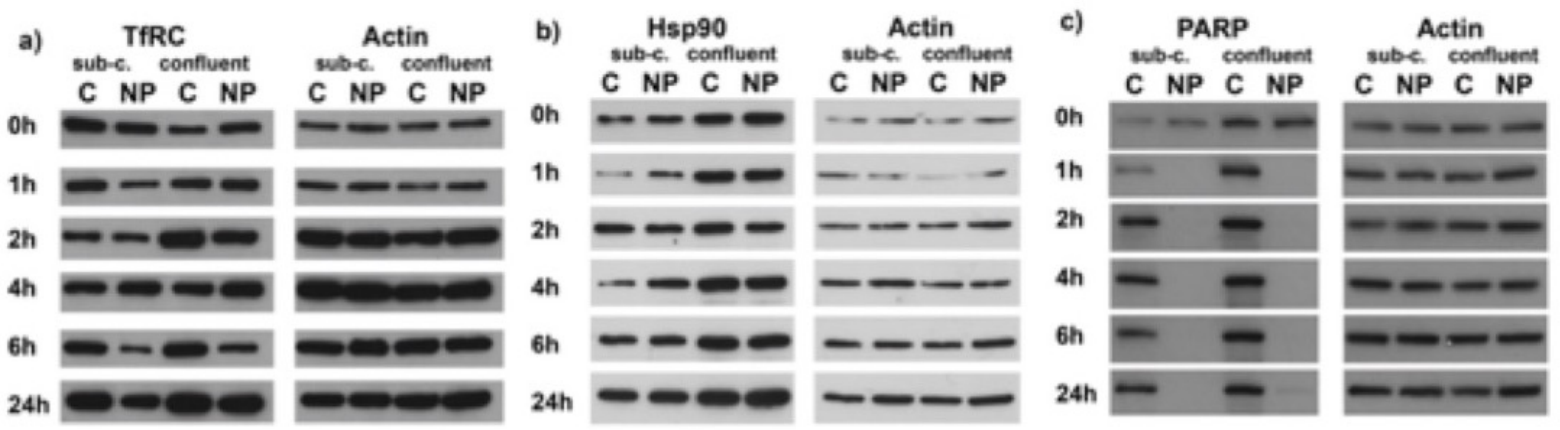

Figure 1. Protein "depletion" in nanoparticle treated samples. The quantities of TfRC (a), Hsp90 (b), and PARP (c) in whole cell lysates from nanoparticle treated and parallel control cells were evaluated by Western blots. Protein depletion in nanoparticle treated samples compared to their non-treated counterparts is most likely caused by the formation of protein corona on the surface of nanoparticles and subsequent removal of nanoparticles from the cell lysate mixtures in the course of the protein isolation procedure. Samples came from HeLa cells grown in T25 flasks to sub-confluent (sub-c.) or confluent (confluent) density and left untreated (C) or treated with nanoparticles (NP). Cells were harvested immediately (0 hours) or incubated in the presence of nanoparticles for 1, 2, 4, 6 or 24 hours before protein harvest (Western blot rows). 
Considering the rapid and persistent loss of PARP from protein cell extracts of nanoparticle treated cells and the possibility that the apparent PARP decrease (and possibly TfRC changes as well) may be due to its participation in nanoparticle protein corona - we modified our protein isolation approach (see Methods). We processed pellets from protein isolation at the 2hour timepoint like what was done when cell extracts were mixed with nanoparticles. Several washes of the pellet were done, followed by the "elution" step. Next, protein extracts, washes and eluates were probed with antibodies for
TfRC, Hsp90 and PARP (Figure 2). Interestingly - while progressive washes of pellets from nanoparticle treated cells showed decreasing amounts of all three test proteins as well as actin, final elution step released a significant amount of TfRC, PARP and actin, but not Hsp90. Hsp90 may participate in nanoparticle corona, as well as several other heat shock proteins: Hsp70, Hsp60, Hsp47, shown in Supplemental Table 1, only loosely because other proteins adhering to nanoparticles appear as if though they are heat-shock denatured.

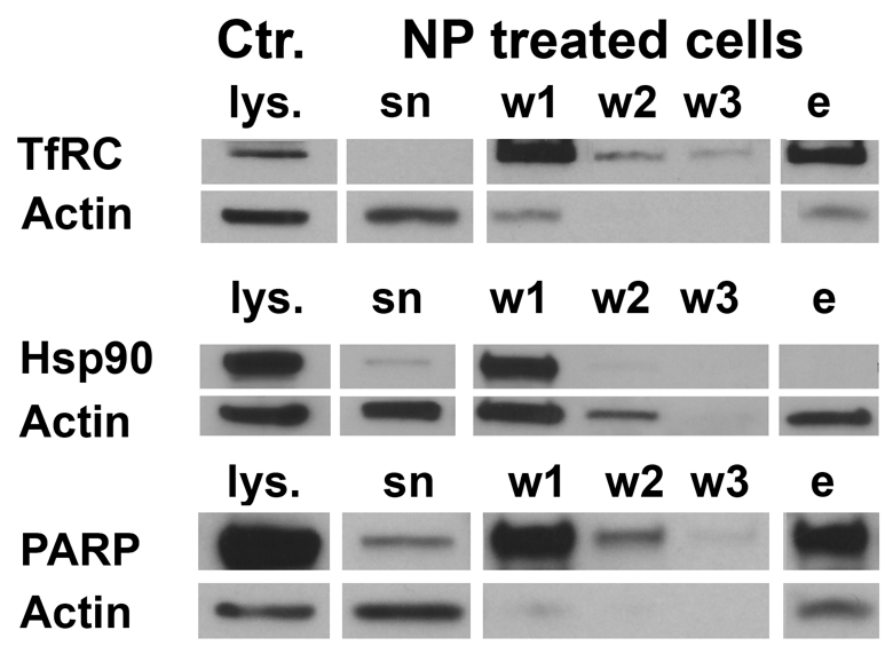

Figure 2. The protein corona accumulated on nanoparticles inside cells was stripped by sequential washes and elution steps. The first lane shows the lysate (lys.) as prepared from cells not treated with nanoparticles, followed by supernatant (sn) - cell lysate from nanoparticle treated cells obtained after centrifugation step that precipitates nanoparticles with proteins that form the corona. Nanoparticle pellets were washed and re-precipitated; each time the supernatant "wash" solution contained some of the proteins forming nanoparticle corona (w1-3). The final "elution" (e) with heating stripped some of the remaining protein corona from the nanoparticles. The proteins present in "elution" lanes were attached to the nanoparticles strongly enough to withstand room temperature washes with Laemmli buffer. These experiments were repeated three times and representative data is shown.

To explore the interaction between PARP and nanoparticles still further - we treated cells at sub-confluent density with nanoparticles for 2 hours and then exposed them to staurosporine for 4 hours at below-toxic $(0.1$ and $0.01 \mu \mathrm{M})$ and toxic $(1 \mu \mathrm{M})$ concentrations. While toxic concentrations of staurosporine led to the activation of caspase 3 and subsequent PARP cleavage as expected [38], neither whole PARP nor the large cleaved fragment of PARP were present in cell lysates from cells treated with nanoparticles (Figure 3). This experiment documented that interaction between PARP and nanoparticles persists through caspase 3 activation. In addition, it is also worth noting that under these experimental conditions nanoparticles alone do not induce caspase 3 cleavage nor do they bound caspase 3 .

In addition to individual protein changes in nanoparticle treated cells, we decided to explore cellular processes dependent on the concerted actions of many proteins. When we used DAVID software analysis to screen KEGG pathways that may be affected by nanoparticle protein binding (Supplemental Table 3), pathway hsa03040: Spliceosome, included the most protein members (24), while nucleotide and ribonucleotide binding topped the list of annotation clusters (enrichment score 16.54, Supplemental Table 2). 

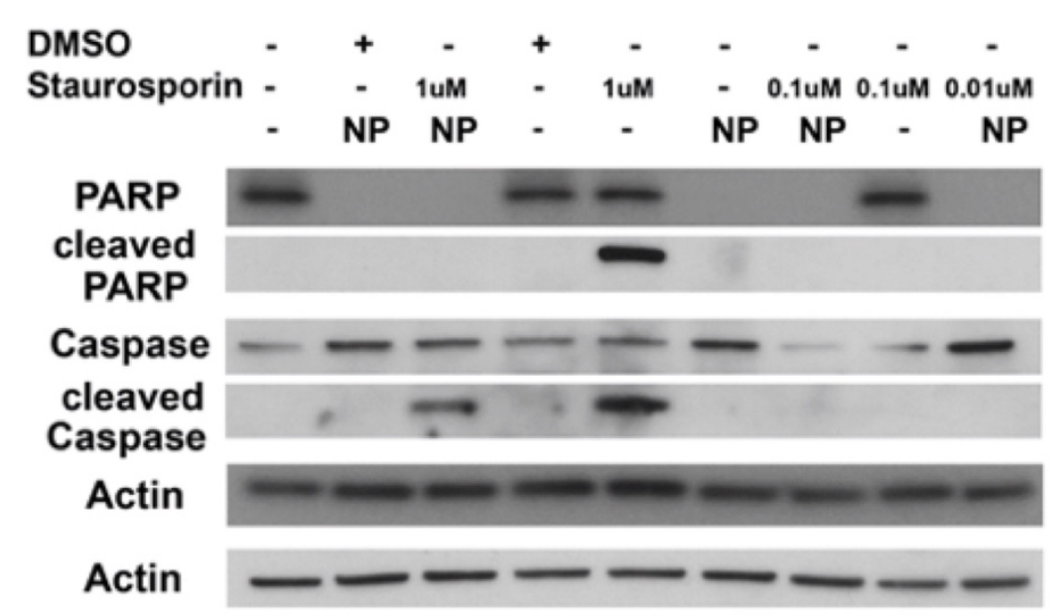

Figure 3. PARP and a large fragment of cleaved PARP are absent in Western blots of protein lysates from nanoparticle treated cells. HeLa cells were exposed to $20 \mu \mathrm{g} / \mathrm{mL}$ of nanoparticles for 2 hours followed by $1,0.1$ or $0.01 \mu M$ staurosporine dissolved in dimethyl sulfoxide (DMSO) for 4 hours. DMSO was used as a vehicle control. Matching pair of Western blots was done with the same protein lysates loaded in equal amounts and in the same order in both cases. Top row actin blot matches PARP blot, while bottom row actin blot corresponds to blots of cleaved PARP, caspase 3 and cleaved caspase 3. This Western Blot series is a representative example of three experiments.

With this in mind, we anticipated that the nanoparticle presence should change gene expression in general in HeLa cells treated with nanoparticles. We isolated mRNA from cells exposed to nanoparticles for 2 or 4 hours. Three biological and one technical mRNA replicates were done each for the two pairs of nanoparticle-treated and control cells were harvested at 2 or 4 hours.

Table 1. Gene expression in nanoparticle treated cells was evaluated by Illumina arrays.

\begin{tabular}{|c|c|c|c|c|c|}
\hline \multirow[b]{2}{*}{ Gene Symbol } & \multirow[b]{2}{*}{ Gene Name } & \multicolumn{2}{|c|}{ Fold Change } & \multicolumn{2}{|c|}{ Adjusted $\mathrm{p}$ Value } \\
\hline & & $2 \mathrm{~h}$ & $4 \mathrm{~h}$ & & \\
\hline BLOC1S1 & biogenesis of lysosomal organelles complex-1, subunit 1 & 1.415 & & 0.230 & \\
\hline C8orf4 & chromosome 8 open reading frame 4 & 1.693 & & 0.023 & \\
\hline RGS2 & regulator of G-protein signaling 2, 24kDa & 1.424 & & 0.205 & \\
\hline DKK1 & dickkopf 1 homolog (Xenopus laevis) & 1.863 & & 0.392 & \\
\hline PHLDA1 & pleckstrin homology-like domain, family A, member 1 & 2.197 & 1.484 & 0.012 & 0.147 \\
\hline EFNA1 & ephrin-A1 & & 1.466 & & 0.147 \\
\hline GPER & G protein-coupled estrogen receptor 1 & -1.448 & & 0.035 & \\
\hline DDIT4 & DNA-damage-inducible transcript 4 & -1.453 & & 0.023 & \\
\hline TNFSF9 & tumor necrosis factor (ligand) superfamily, member 9 & -1.441 & & 0.134 & \\
\hline CA9 & carbonic anhydrase IX & -1.419 & -1.443 & 0.134 & 0.105 \\
\hline DUSP2 & dual specificity phosphatase 2 & -1.425 & -1.597 & 0.205 & 0.089 \\
\hline HEY1 & hairy/enhancer-of-split related with YRPW motif 1 & -1.470 & -1.489 & 0.044 & 0.031 \\
\hline ID1 & inhibitor of DNA binding 1, dominant negative helix-loop-helix protein & -3.473 & -3.265 & 0.000 & 0.000 \\
\hline ID2 & inhibitor of DNA binding 2, dominant negative helix-loop-helix protein & -1.542 & -1.681 & 0.031 & 0.013 \\
\hline ID3 & inhibitor of DNA binding 3, dominant negative helix-loop-helix protein & -2.454 & -2.251 & 0.000 & 0.000 \\
\hline SMAD6 & SMAD family member 6 & -1.488 & -1.478 & 0.031 & 0.022 \\
\hline TFRC & transferrin receptor (p90, CD71) & -1.481 & -2.252 & 0.044 & 0.000 \\
\hline NDUFA4L2 & NADH dehydrogenase (ubiquinone) 1 alpha subcomplex, 4 -like 2 & & -1.492 & & 0.070 \\
\hline PFKFB4 & 6-phosphofructo-2-kinase/fructose-2,6-biphosphatase 4 & & -1.470 & & 0.022 \\
\hline PLIN2 & perilipin 2 & & -1.444 & & 0.132 \\
\hline $\mathrm{CDH} 10$ & cadherin 10 , type 2 (T2-cadherin) & & -1.636 & & 0.055 \\
\hline DIO2 & deiodinase, iodothyronine, type II & & -1.442 & & 0.028 \\
\hline
\end{tabular}

Three biological replicates of each sample were processed by Illumina arrays. The data was subjected to ComBat [39] to remove batch effects; Limma model [40] was used for differential expression analysis; the use of these corrections resulted in adjusted $p$ values shown. This small group of mRNAs was shown to have stable statistically significant changes in expression. Illumina array results were confirmed by real time PCR as well (Figure 4). 
While RNA quality and individual array results were good (see Methods section), mRNA expression differences were subtle and batch effects could be noted for technical replicates hybridized to Illumina arrays on two separate occasions. Raw array data are available at the NIH hosted Gene Expression database (www.ncbi.nlm.nih.gov/geo/) under accession number GSE88786. A rigorous analysis was done to minimize batch differences (see Methods) and a group of 22 mRNAs was found to be consistently affected by nanoparticle treatments (Table 1). Further analysis using these 22 genes with DAVID software showed only two annotation clusters with enrichment scores better than 1 (Supplemental Table 4). Interestingly, TfRC mRNA was one of the RNAs on this listQuantitative RT-PCR (Figure 4) was done with RNA isolates prepared independently of RNAs used for microarray analyses. A a sub- group of mRNAs differentially expressed on Illumina arrays, either "robustly" according to our array post-analysis: Dual specificity phosphatase 2 (DUSP2), G protein coupled estrogen receptor (GPER), inhibitors of DNA binding 1, 2 and 3 (ID1, ID2 and ID3) and TfRC) or not. The latter group included Frizzled-9 (FZD9), mitogen activated protein kinase kinase kinase (Map3K) and single strand selective monofunctional Uracil-DNA glycosylase (SMUG1), as well as Hsp90 and PARP. While gene expression of the latter group of genes did not show changes robust enough to pass our Illumina array post-analysis, expression of many of these genes was modulated in response to nanoparticle treatments albeit mildly. It should be noted that TfRC gene expression values on Illumina array $(-1.5$ at $2 \mathrm{~h}$ and -2.3 at $4 \mathrm{~h})$ match QRTPCR.

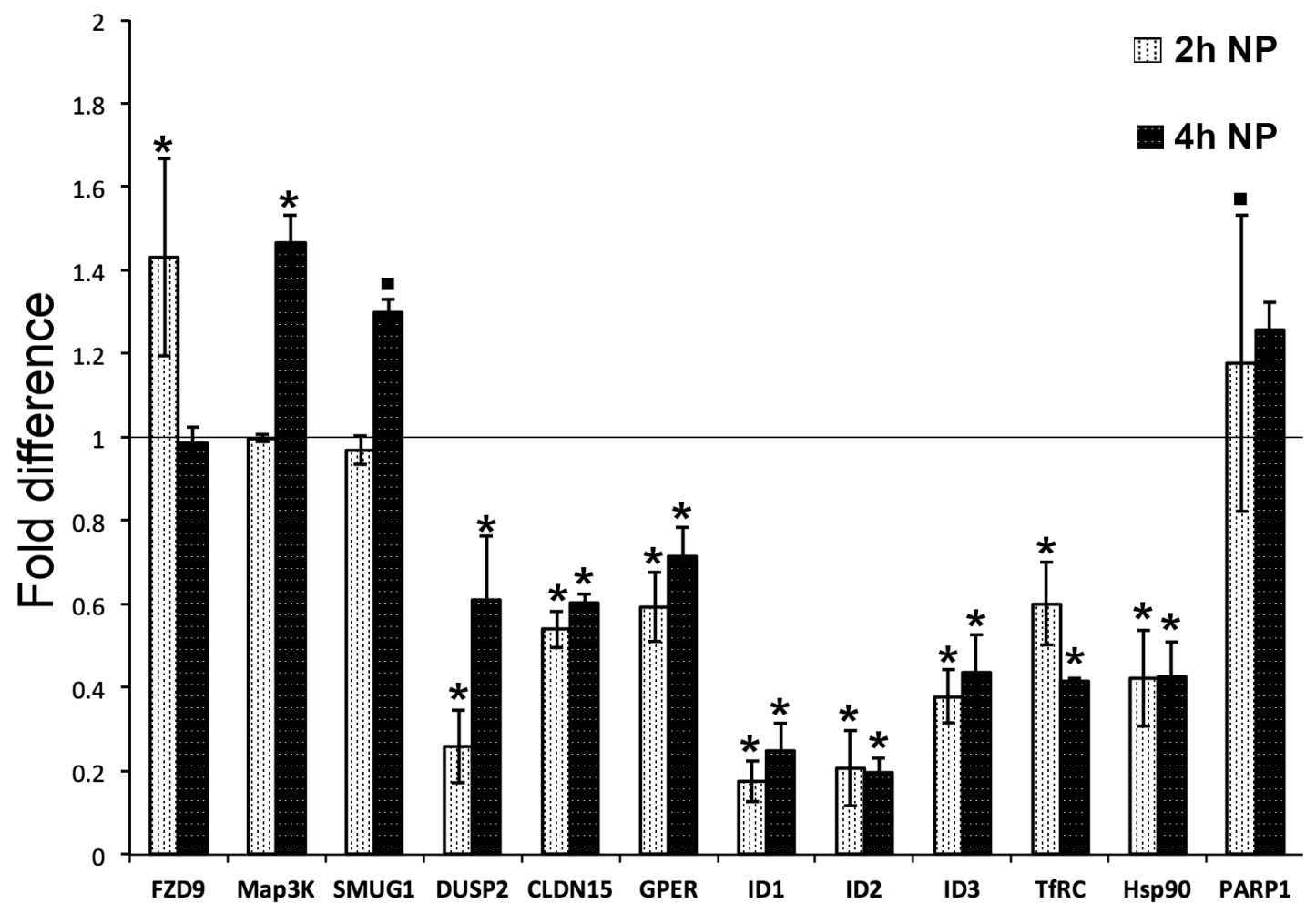

Figure 4. Quantitative real time PCR was used to corroborate the findings of Illumina microarray analysis. Gene expression after $2 \mathrm{~h}$ or $4 \mathrm{~h}$ of nanoparticle exposure was compared to gene expression in control cells, which was set to the value of 1 (represented by the thin horizontal line in the graph). Bars represent averages of three biological replicates (each biological replicate corresponds to three or more technical replicates by $P C R)$, error bars show standard deviation. $P$ values were calculated for each set of technical PCR replicates. To show statistical significance, bars with a $p$ value less than 0.005 are labeled with an asterisk, while bar labeled with a square dot had a p value less than 0.05 in one experiment and less than 0.005 in two other experiments. 


\section{Discussion}

While targeted nanoparticles often mimic different ligands (e.g. epidermal growth factor [8]) and engage suitable endocytic pathways, nontargeted nanoparticles frequently enter cells through multiple endocytic pathways $[7,19]$ or via GAP junctions [6]. Different endocytic mechanisms transfer nanoparticles to different subcellular compartments where they have a chance to engage in interactions with many cellular proteins. This study began with mixing nanoparticles with cell lysates. Only a portion of these proteins were analyzed, with more than 250 proteins identified (Supplemental Table 1). It is important to note that among the nanoparticle interacting proteins we found some that we have previously explored in studies with nontargeted nanoparticles (e.g. proteasome as in [16]), but none that were found in work with targeted nanoparticles $[8,28]$. Three of these proteins: TfRC, Hsp90 and PARP were found also in nanoparticle protein coronas when nanoparticles were used for treatments of whole live cells in cell culture. Interestingly, retention of these proteins in nanoparticle corona varied significantly - the least stable corona participant was Hsp90 and the most stable PARP. This protein was almost completely absent from lysates of nanoparticle treated cells over period as long as 24 hours (Figure 1).

A study by Gagne and others [41] focused on discovery of proteins that are covalently poly(ADP-ribosyl)ated or bind PARP noncovalently, settled on the amino acid sequence:
$[\mathrm{HKR}]_{1}-\mathrm{X}_{2}-\mathrm{X}_{3}-[\mathrm{AQVY}]_{4-}[\mathrm{KR}]_{5-}[\mathrm{KR}]_{6}-[\mathrm{AI} \mathrm{LV}]_{7}$ - [FILPV] 8 as a conservative version of consensus pADPr motif. Since we can note several arginine and lysine amino acids in this PARP binding sequence [41], it is possible that the numerous $\mathrm{NH}_{2}$ groups of dopamine molecules covering the nanoparticle surface could mimic PARP binding motifs causing tight binding and depletion of this protein.

Pathway analyses were done with the list of proteins interacting with nanoparticles using tools available on the NIAID-sponsored DAVID website $[42,43]$. This work suggests that many possible cellular activities may be affected by the presence of non-targeted nanoparticles. The second highest annotation cluster (enrichment score 13) points to membrane-enclosed subcellular organelles and this finding supports the concept of "universal" endocytic uptake of non-targeted nanoparticles. Remaining two of the first three annotation clusters (enrichment scores of 16 and 10) included pathways for nucleotide and ribonucleotide binding and RNA binding, spliceosome and RNA processing. Similarly, DAVID software output for KEGG pathways also listed spliceosome as one of the pathways affected by nanoparticle presence. Interestingly, mRNA changes in nanoparticle treated samples at early timepoints after nanoparticle treatment, when the relative contribution of spliceosome should be more pronounced than possible transcription associated changes, were subtle and gene expression differences rarely amounted to more than 1.5 -fold.

\section{Conclusion}

In conclusion, this study shows that non-targeted nanoparticles can interact with numerous cellular proteins and impact cellular processes resulting in subtle gene expression changes. While none of the effects we find are overwhelming other cellular activities nor could be considered cytotoxic, changes occur in many cellular pathways and should be explored in combination with other cell stresses.

\section{Conflict of Interests}

The authors declare no conflicts of interest. For signed statements, please contact the journal office: editor@precisionnanomedicine.com

\section{Acknowledgements:}

This research was supported by the National Institutes of Health under the following Grant Numbers CA107467, EB002100 and U54CA119341. CURE supplement awards to the Robert H. Lurie Comprehensive Cancer Center supported B.G. P30 CA060553 - 21S1; S.M. P30 CA060553 - 20S3; and J.F. P30 CA060553 - 19S1F. F.R.Jr. was supported by funds provided by the Graduate School as part of the Summer Research Opportunity Program (SROP). The authors thank Ms. Charlene Wilke from the Biological Imaging Facility at Northwestern University for assistance in TEM imaging. Metal analysis was performed at the 
Northwestern University Quantitative Bio-element Imaging Center generously supported by NASA Ames Research Center NNA06CB93G. Use of the Simpson Querrey Institute Analytical BioNanoTechnology Equipment Core (ANTEC) facility was supported by the U.S. Army Research Office, the U.S. Army Medical Research and Materiel Command, and Northwestern University funding received from the Soft and Hybrid Nanotechnology Experimental (SHyNE) Resource (NSF NNCI-1542205).

\section{Author contributions:}

R.O.L. ${ }^{1}$, T.P. ${ }^{2}$ and G.E.W. ${ }^{3}$ conceived and designed the experiments; B.G. ${ }^{4}$ S.M ${ }^{5}$. and R.O.L. performed RNA experiments and qPCR; F.R. ${ }^{6}$, J.F. $^{7}$ and R.O.L. performed Western Blot experiments; L.X. ${ }^{8}$, K.B. ${ }^{9}$ performed nanoparticle characterization, Y.B. ${ }^{10}$ analyzed microarray data, D.N. ${ }^{11}$ performed mass spectrometry and analysis, S.R. ${ }^{12}$ and M.P. ${ }^{13}$ provided technical support and conceptual advice. R.O.L. and T.P. wrote the manuscript. G.W. supervised all the projects. All authors discussed the results and commented on the manuscript.

Quote this article as: Lastra RO, Paunesku T, Gutama B, Reyes F, Jr., François J, Martinez S, Xin L, Brown K, Zander A, Raha S, Protic M, Nanavati D, Bi YT, Woloschak GE, Protein Binding Effects of Dopamine Coated Titanium Dioxide Shell Nanoparticles, Precis. Nanomed. 2019;2(4):393-438, https://doi.org/10.33218/prnano2(4).190802.1

\footnotetext{
${ }^{1}$ Ruben Omar Lastra, Department of Radiation Oncology Feinberg School of Medicine, Northwestern University, Chicago, Illinois 60611, United States r-lastra@,northwestern.edu

${ }^{2}$ Tatjana Paunesku, Department of Radiation Oncology Feinberg School of Medicine, Northwestern University, Chicago, Illinois 60611, United States, tpaunesku@northwestern.edu

${ }^{3}$ Gayle E Woloschak, Department of Radiation Oncology, Feinberg School of Medicine, Northwestern University, Chicago, Illinois 60611, United States, g-woloschak@northwestern.edu

${ }^{4}$ Barite Gutama, Present Address: Department of Chemistry, St. Olaf College, Northfield, Minnesota, 55057, United States, gutama@stolaf.edu

${ }^{5}$ Shelby Martinez Present Address: Department of Molecular and Cellular Biology, Harvard University, Cambridge, Massachusetts, 02138 United States, shelbymartinez@college.harvard.edu

${ }^{6}$ Filiberto Reyes, Jr., Present Address: School of Natural Sciences and Mathematics, California State University, Fullerton, California, 92831, United States, filyreyes@csu.fullerton.edu

${ }^{7}$ Josie François, Present Address: Department of Chemistry, Harvard University, Cambridge, Massachusetts, 02138 United States, jfran824@gmail.com

${ }^{8}$ Lun Xin a , Present Address: Cook Pharmica LLC, Bloomington, Indiana 47403, United States, LunXin2015@u.northwestern.edu

${ }^{9}$ Koshonna Brown, Present Address: Daiichi Sankyo, Basking Ridge, NJ 07920, United States, kobrown@dsi.com, KoshonnaBrown2013@u.northwestern.edu

${ }^{10}$ Yingtao Bi, Department of Biomedical Informatics, Feinberg School of Medicine, Northwestern University, Chicago, Illinois 60611, United States, yingtao.bi@northwestern.edu

11 Dhaval Nanavati, Present Address: AbbVie, Worcester, MA 01605, United States, d-nanavati@northwestern.edu

${ }^{12}$ Sumita Raha, Present Address: Rush University Medical Center, Chicago, IL 60612, United States, sumitaraha@gmail.com

${ }^{13}$ Miroslava Protic, Department of Radiation Oncology Feinberg School of Medicine, Northwestern University, Chicago, Illinois 60611, United States, mprotic129@gmail.com
} 


\section{References}

[1] E. J. Petersen et al., "Identification and Avoidance of Potential Artifacts and Misinterpretations in Nanomaterial Ecotoxicity Measurements," (in English), Environmental Science \& Technology, Review vol. 48, no. 8, pp. 4226-4246, Apr 2014.

[2] M. P. Monopoli, C. Aberg, A. Salvati, and K. A. Dawson, "Biomolecular coronas provide the biological identity of nanosized materials," Nat Nanotechnol, vol. 7, no. 12, pp. 779-86, Dec 2012.

[3] M. Lundqvist et al., "The evolution of the protein corona around nanoparticles: a test study," ACS Nano, vol. 5, no. 9, pp. 7503-9, Sep 272011.

[4] M. Karimi et al., "Smart micro/nanoparticles in stimulus-responsive drug/gene delivery systems," Chem Soc Rev, vol. 45, no. 5, pp. 1457-501, Mar 72016.

[5] V. Mirshafiee, M. Mahmoudi, K. Lou, J. Cheng, and M. L. Kraft, "Protein corona significantly reduces active targeting yield," Chem Commun (Camb), vol. 49, no. 25, pp. 2557-9, Mar 282013.

[6] M. I. Setyawati et al., "Titanium dioxide nanomaterials cause endothelial cell leakiness by disrupting the homophilic interaction of VE-cadherin," Nat Commun, vol. 4, p. 1673, 2013.

[7] E. Huerta-Garcia et al., "Internalization of titanium dioxide nanoparticles by glial cells is given at short times and is mainly mediated by actin reorganization-dependent endocytosis," Neurotoxicology, vol. 51, pp. 27-37, Dec 2015.

[8] Y. Yuan et al., "Epidermal growth factor receptor targeted nuclear delivery and high-resolution whole cell X-ray imaging of Fe3O4@TiO2 nanoparticles in cancer cells," (in eng), ACS Nano, vol. 7, no. 12, pp. 10502-17, Dec 232013.

[9] R. Bazak et al., "Cytotoxicity and DNA cleavage with core-shell nanocomposites functionalized by a KH domain DNA binding peptide," Nanoscale, vol. 5, no. 23, pp. 11394-9, Dec 72013.

[10] T. Paunesku et al., "Gadolinium-conjugated TiO2-DNA oligonucleotide nanoconjugates show prolonged intracellular retention period and $\mathrm{T} 1$-weighted contrast enhancement in magnetic resonance images," (in eng), Nanomedicine, vol. 4, no. 3, pp. 201-7, Sep 2008.

[11] E. M. B. Brown et al., "Methods for assessing DNA hybridization of peptide nucleic acidtitanium dioxide nanoconjugates," (in English), Analytical Biochemistry, vol. 383, no. 2, pp. 226-235, Dec 152008.

[12] A. G. Wu et al., "Titanium dioxide nanoparticles assembled by DNA molecules hybridization and loading of DNA interacting proteins," (in English), Nano, vol. 3, no. 1, pp. 27-36, Feb 2008.

[13] P. J. Endres, T. Paunesku, S. Vogt, T. J. Meade, and G. E. Woloschak, "DNA-TiO2 nanoconjugates labeled with magnetic resonance contrast agents," (in English), Journal of the American Chemical Society, vol. 129, no. 51, pp. 15760-+, Dec 262007.

[14] T. Paunesku et al., "Intracellular distribution of TiO2-DNA oligonucleotide nanoconjugates directed to nucleolus and mitochondria indicates sequence specificity," (in eng), Nano Lett, vol. 7, no. 3, pp. 596-601, Mar 2007.

[15] T. Paunesku et al., "Biology of TiO2-oligonucleotide nanocomposites," (in eng), Nat Mater, vol. 2, no. 5, pp. 343-6, May 2003.

[16] C. A. Falaschetti et al., "Negatively charged metal oxide nanoparticles interact with the 20S proteasome and differentially modulate its biologic functional effects," ACS Nano, vol. 7, no. 9, pp. 7759-72, Sep 242013.

[17] H. C. Arora et al., "Nanocarriers enhance Doxorubicin uptake in drug-resistant ovarian cancer cells," (in eng), Cancer Res, vol. 72, no. 3, pp. 769-78, Feb 012012.

[18] K. T. Thurn et al., "Labeling TiO2 nanoparticles with dyes for optical fluorescence microscopy and determination of TiO2-DNA nanoconjugate stability," (in eng), Small, vol. 5, no. 11, pp. 1318-25, Jun 2009. 
[19] K. T. Thurn et al., "Endocytosis of titanium dioxide nanoparticles in prostate cancer PC-3M cells," Nanomedicine, vol. 7, no. 2, pp. 123-30, Apr 2011.

[20] T. Suzuki et al., "Genotoxicity assessment of intravenously injected titanium dioxide nanoparticles in gpt delta transgenic mice," (in eng), Mutat Res Genet Toxicol Environ Mutagen, vol. 802, pp. 30-7, May 2016.

[21] M. Reis Ede et al., "Evaluation of titanium dioxide nanocrystal-induced genotoxicity by the cytokinesis-block micronucleus assay and the Drosophila wing spot test," (in eng), Food Chem Toxicol, vol. 96, pp. 309-19, Oct 2016.

[22] C. Chakraborty, A. R. Sharma, G. Sharma, and S. S. Lee, "Zebrafish: A complete animal model to enumerate the nanoparticle toxicity," (in eng), J Nanobiotechnology, vol. 14, no. 1, p. 65, 2016.

[23] N. Asare et al., "Genotoxicity and gene expression modulation of silver and titanium dioxide nanoparticles in mice," (in eng), Nanotoxicology, vol. 10, no. 3, pp. 312-21, 2016.

[24] H. Cowie et al., "Suitability of human and mammalian cells of different origin for the assessment of genotoxicity of metal and polymeric engineered nanoparticles," (in eng), Nanotoxicology, vol. 9 Suppl 1, pp. 57-65, May 2015.

[25] C. Uboldi et al., "Role of the crystalline form of titanium dioxide nanoparticles: Rutile, and not anatase, induces toxic effects in Balb/3T3 mouse fibroblasts," (in eng), Toxicol In Vitro, vol. 31, pp. 137-45, Mar 2016.

[26] L. P. Franchi et al., "Cyto- and genotoxic effects of metallic nanoparticles in untransformed human fibroblast," (in eng), Toxicol In Vitro, vol. 29, no. 7, pp. 1319-31, Oct 2015.

[27] A. Zijno et al., "Different mechanisms are involved in oxidative DNA damage and genotoxicity induction by $\mathrm{ZnO}$ and $\mathrm{TiO} 2$ nanoparticles in human colon carcinoma cells," Toxicol In Vitro, vol. 29, no. 7, pp. 1503-12, Oct 2015.

[28] Y. Yuan et al., "Mapping the subcellular localization of FeO@TiO nanoparticles by X-ray Fluorescence Microscopy," J Phys Conf Ser, vol. 463, 2013.

[29] J. P. Holmberg, E. Ahlberg, J. Bergenholtz, M. Hassellov, and Z. Abbas, "Surface charge and interfacial potential of titanium dioxide nanoparticles: Experimental and theoretical investigations," Journal of Colloid and Interface Science, vol. 407, pp. 168-176, Oct 2013.

[30] Z. Abbas et al., "Synthesis, characterization and particle size distribution of $\mathrm{TiO} 2$ colloidal nanoparticles," Colloids and Surfaces a-Physicochemical and Engineering Aspects, vol. 384, no. 1-3, pp. 254-261, Jul 2011.

[31] T. Rajh, L. X. Chen, K. Lukas, T. Liu, M. C. Thurnauer, and D. M. Tiede, "Surface Restructuring of Nanoparticles: An Efficient Route for Ligand-Metal Oxide Crosstalk," The Journal of Physical Chemistry B, vol. 106, no. 41, pp. 10543-10552, 2002/10/01 2002.

[32] A. Michelmore, W. Q. Gong, P. Jenkins, and J. Ralston, "The interaction of linear polyphosphates with titanium dioxide surfaces," (in English), Physical Chemistry Chemical Physics, Article vol. 2, no. 13, pp. 2985-2992, 2000.

[33] S. E. Kim et al., "Ultrasmall nanoparticles induce ferroptosis in nutrient-deprived cancer cells and suppress tumour growth," (in Eng), Nat Nanotechnol, Sep 262016.

[34] A. Widera, F. Norouziyan, and W. C. Shen, "Mechanisms of TfR-mediated transcytosis and sorting in epithelial cells and applications toward drug delivery," Adv Drug Deliv Rev, vol. 55, no. 11, pp. 1439-66, Nov 142003.

[35] K. Terasawa, M. Minami, and Y. Minami, "Constantly updated knowledge of Hsp90," J Biochem, vol. 137, no. 4, pp. 443-7, Apr 2005.

[36] J. Morales et al., "Review of poly (ADP-ribose) polymerase (PARP) mechanisms of action and rationale for targeting in cancer and other diseases," Crit Rev Eukaryot Gene Expr, vol. 24, no. 1, pp. 15-28, 2014.

[37] L. Virag, A. Robaszkiewicz, J. M. Rodriguez-Vargas, and F. J. Oliver, "Poly(ADP-ribose) signaling in cell death," Mol Aspects Med, vol. 34, no. 6, pp. 1153-67, Dec 2013. 
[38] D. W. Nicholson et al., "Identification and Inhibition of the Ice/Ced-3 Protease Necessary for Mammalian Apoptosis," (in English), Nature, vol. 376, no. 6535, pp. 37-43, Jul 61995.

[39] W. E. Johnson, C. Li, and A. Rabinovic, "Adjusting batch effects in microarray expression data using empirical Bayes methods," (in English), Biostatistics, vol. 8, no. 1, pp. 118-127, Jan 2007.

[40] M. E. Ritchie et al., "limma powers differential expression analyses for RNA-sequencing and microarray studies," (in English), Nucleic Acids Research, vol. 43, no. 7, Apr 202015.

[41] J. P. Gagne et al., "Proteome-wide identification of poly(ADP-ribose) binding proteins and poly(ADP-ribose)-associated protein complexes," (in eng), Nucleic Acids Res, vol. 36, no. 22, pp. 6959-76, Dec 2008.

[42] D. W. Huang, B. T. Sherman, and R. A. Lempicki, "Bioinformatics enrichment tools: paths toward the comprehensive functional analysis of large gene lists," (in English), Nucleic Acids Research, vol. 37, no. 1, pp. 1-13, Jan 2009.

[43] D. W. Huang, B. T. Sherman, and R. A. Lempicki, "Systematic and integrative analysis of large gene lists using DAVID bioinformatics resources," (in English), Nature Protocols, vol. 4, no. 1, pp. 44$57,2009$. 


\section{Supporting Information}
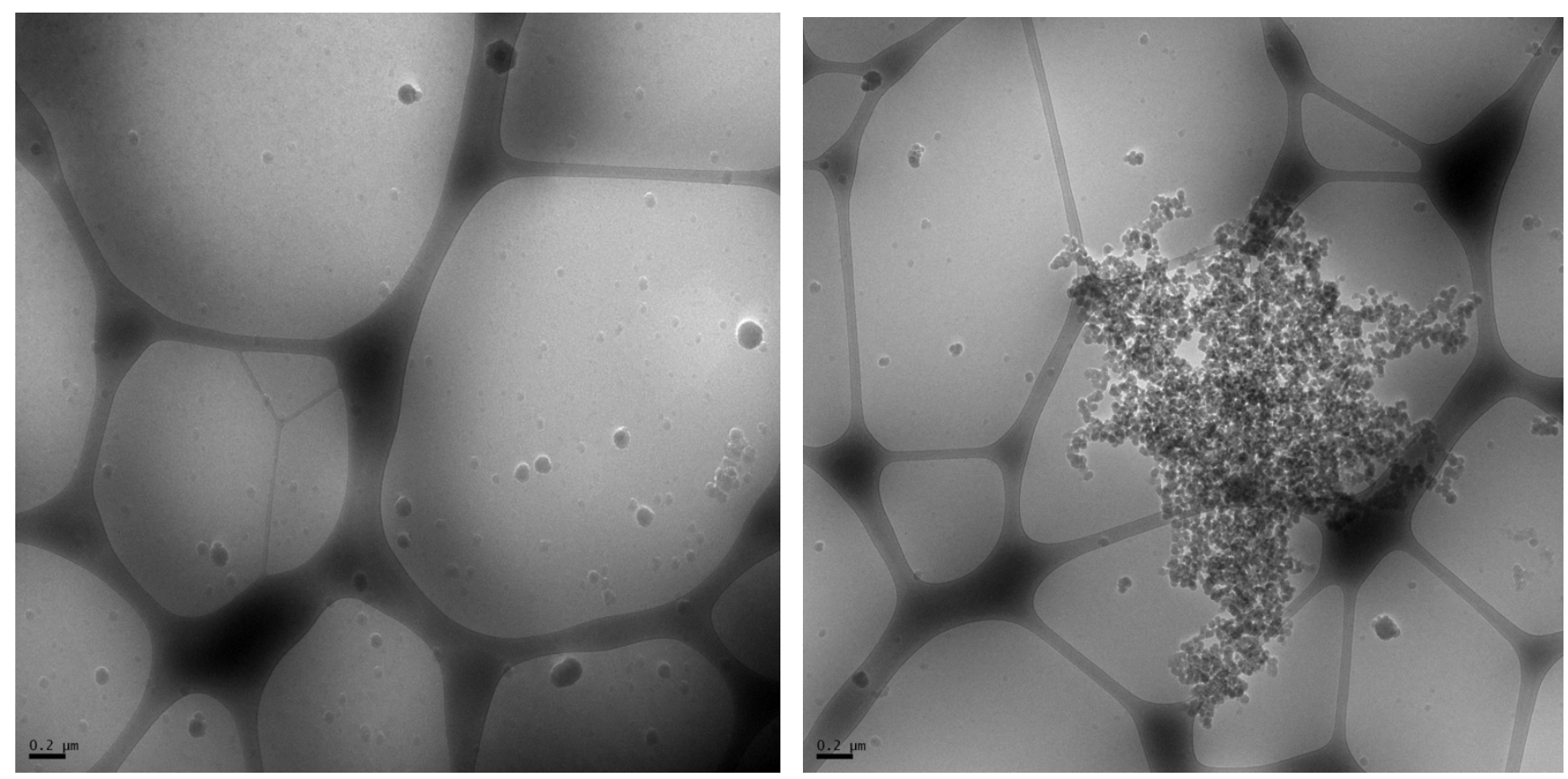

Supplemental Figure 1. Cryo TEM images of two batches of nanoparticles coated with DOPA acquired at 4000x magnification. Note that nanoparticle aggregates overall vary from few $\mathrm{nm}$ to $100 \mathrm{~nm}$. Fewer and smaller aggregates are found in recently prepared batch of nanoparticles (left) than in samples of nanoparticles coated with DOPAC more than 24 months ago (right). Experiments presented in this work were done with nanoparticles prepared within 6 months before use. Nanoparticles were diluted 1:50 with filtered $\mathrm{dH} 2 \mathrm{O}$, drop-cast on lacey carbon TEM grids and plunge-frozen in liquid ethane using a FEI Vitrobot. Cryo transmission electron microscopy was performed on a JEOL $1230120 \mathrm{kV}$ Transmission Electron Microscope at the Northwestern University Biological Imaging Facility.

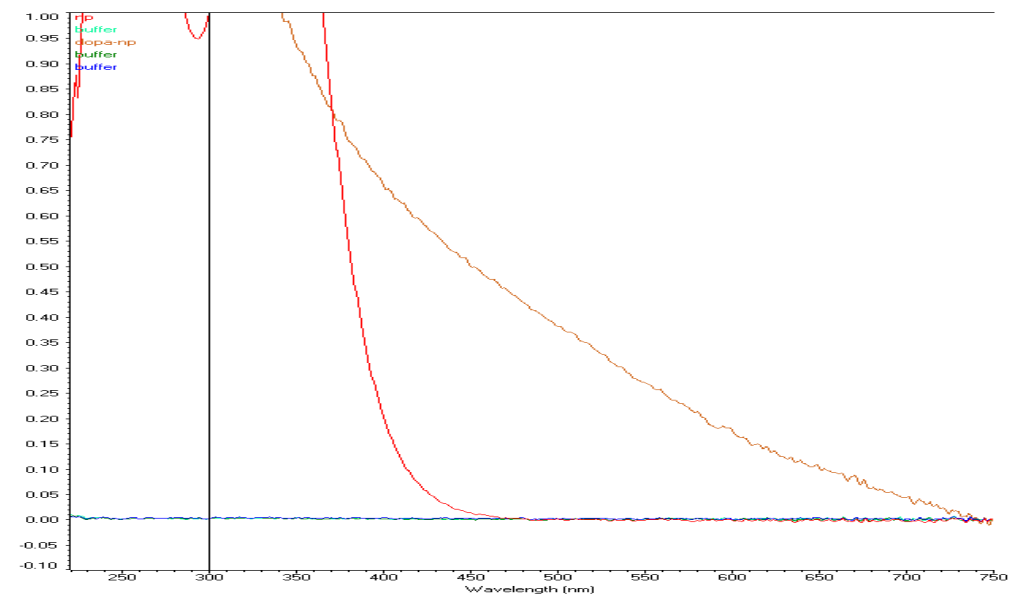

Supplemental Figure 2. UV-vis spectra of dopamine covered (brown) vs. bare (red) nanoparticles. Red shift is a characteristic change of surface coated TiO2 shell nanoparticles [1]. Studies with other nanoparticles with TiO2 surface or pure TiO2 with features smaller than $10 \mathrm{~nm}$ have shown that modification with catechol carrying molecules (and especially dopamine and DOPAC) is covalent and stable both "on the shelf" and inside cells [1-11]. On the other hand, binding of molecules with 
single hydroxyl groups that are not arranged in catechol configuration (e.g. Adriamycin) is labile and such molecules dissociate from nanoparticles inside cells [12].

Amount of dopamine was calculated to cover nanoparticles was calculated based on molarity of nanoparticles and the number of available surface sites for this nanoparticle size (assuming average size of 10nm, calculated based on ICP-MS data and cryo-TEM sizing as previously $[11,12])$. In order to ensure removal of unbound dopamine and bring the $\mathrm{pH}$ of the nanoparticle solution close to neutral, dopamine covered nanoparticles were dialyzed in a series of $10 \mathrm{mM}$ sodium phosphate $40 \mathrm{mM}$ sodium chloride buffer $\mathrm{pH}=4.5$. While chloride and phosphate ions were available to neutralize NH3+ group of dopamine, it should be noted that, if any of the $\mathrm{TiO} 2$ molecules on nanoparticle surface were free at the type of dialysis, they could have bound to phosphates through hydrogen bonds [13].

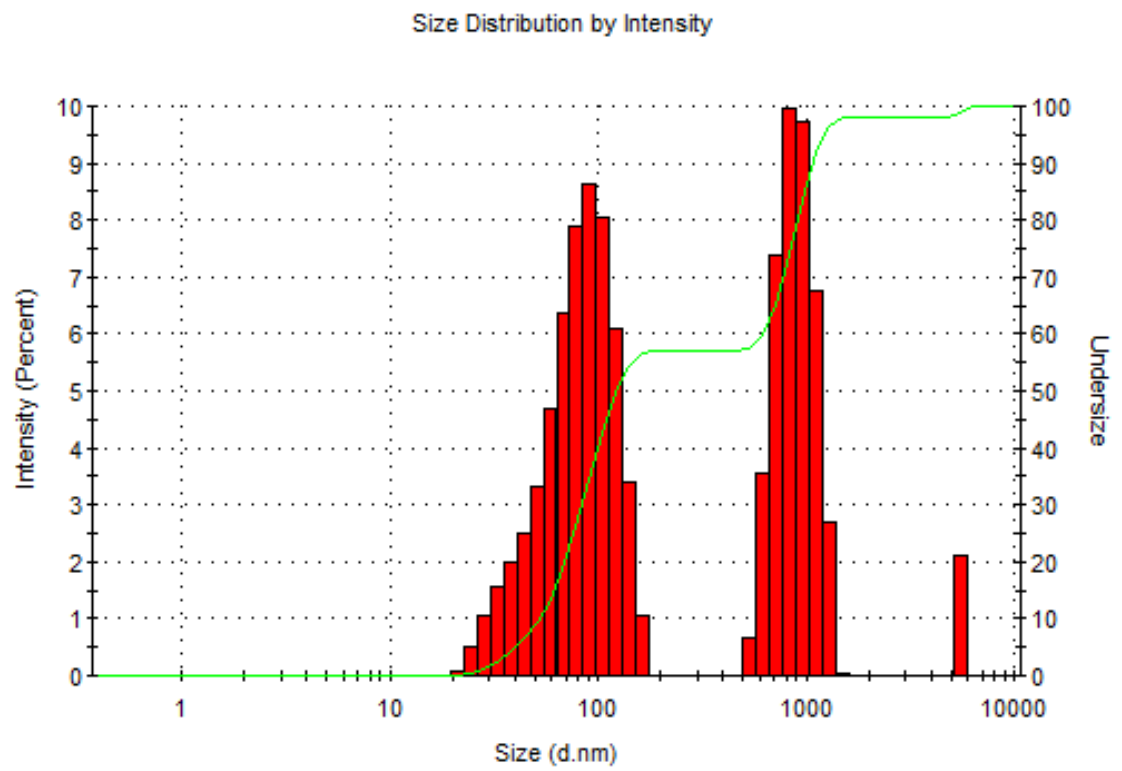

Supplemental Figure 3. Dynamic light scattering (DLS) of dopamine covered nanoparticles diluted in $10 \mathrm{mM} \mathrm{NaCl} \mathrm{buffer.} \mathrm{It}$ should be noted that in addition to dopamine coating, these nanoparticles were also dialyzed in sodium phosphate $\mathrm{pH}=6 \mathrm{prior}$ to evaluation by DLS and use in cells. This process ensured that the $p H$ of the nanoparticle solution is close to neutral; at the same time, electropositive nanoparticle surface is partially covered by H2PO4- and HPO42- ions making the "final" nanoparticles more likely to be neutral and form aggregates. Dopamine covered nanoparticles were diluted in $10 \mathrm{mM} \mathrm{NaCl} \mathrm{buffer}$ according to the protocol recommended by the Nanotechnology Characterization Laboratory (NCL) at the National Cancer Institute (NCI). DLS measurement was done with following parameters (temp: $25^{\circ} \mathrm{C}$, viscosity: 0.891, dielectric constant: 78.6, Henry function: 1.5, refractive index: 1.33) on a Zetasizer Nano (Malvern, Worcestershire, United Kingdom) housed at the ANTEC core facility, Northwestern University. 


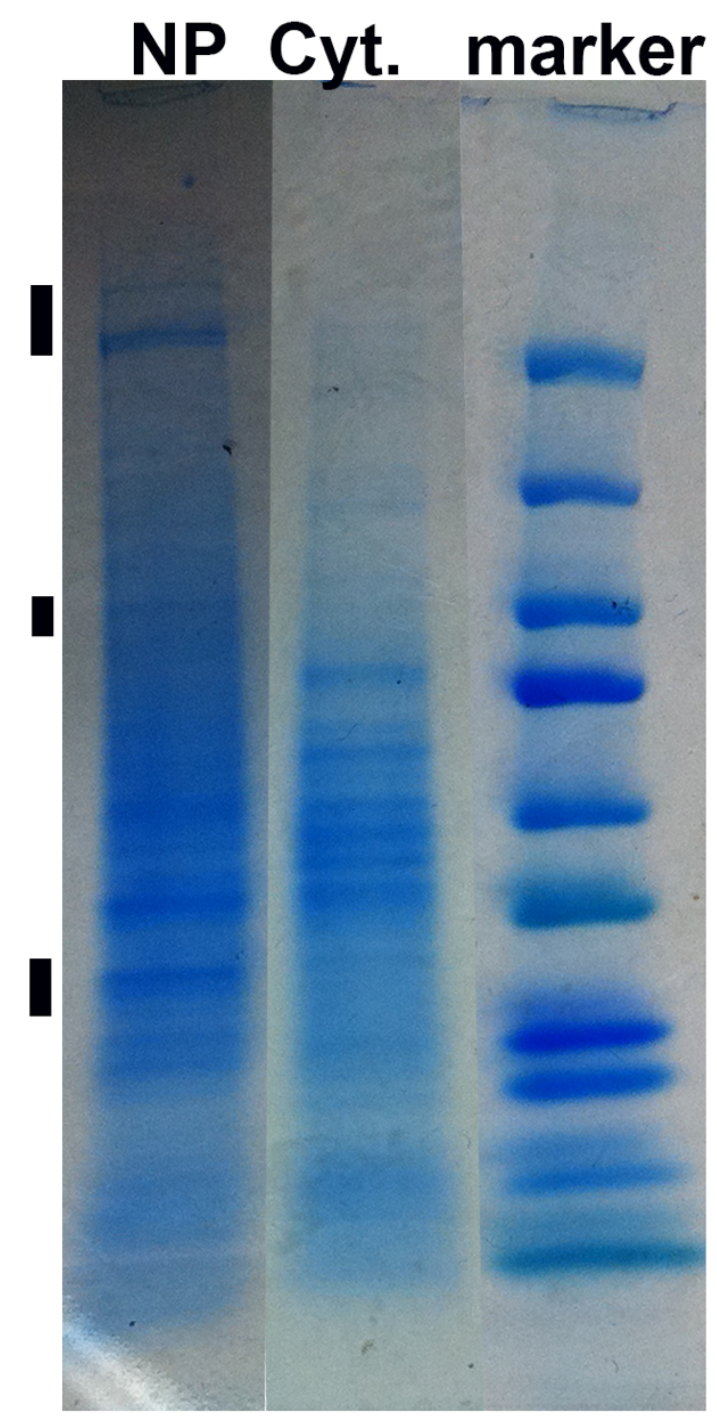

Supplemental Figure 4. Comassie stained gel showing proteins bound to nanoparticles (NP) in comparison to cytoplasmic extracts alone (Cyt.) and prior to band extraction for mass spectrometry. Black bars indicate regions close to $100 \mathrm{kDal}, 70$ $\mathrm{kDal}$ and $30 \mathrm{kDal}$ that were selected for analysis. These areas of gel were chosen because band pattern differed most obviously from no-nanoparticle treatment lane (Cyt.). Similar approach was used to select parts of nanoparticle protein eluates from nanoparticle bound nuclear extracts.

Clarified cytoplasmic and nuclear cell protein extracts (supernatants following centrifugation) from 107 cells were mixed with 500 ul of dopamine coated nanoparticles (approximate nanoparticle molarity $18 \mathrm{nM})$ - and incubated on a slowly rotating mixer overnight. Proteins adhering to nanoparticles were collected by centrifuging the samples at $20 \mathrm{~g}$ for 10 minutes. Pellets of nanoparticles covered with cellular protein corona were washed three times in succession with cell lysis "buffer A" and the final nanoparticle-protein pellet dissolved in gel loading Laemmli buffer and heated at $95^{\circ} \mathrm{C}$ for 5 minutes. Resultant mixtures were cooled, centrifuged once more and the supernatant was loaded directly onto a gel. Several areas of the gel corresponding to protein sizes 30-35 kDal, 70-75 kDal and 100-110 KDal were extracted and submitted for MS analysis. Protein identification based on peptide signatures identified by Proteome Discoverer was done against Swiss-Prot database. All identified protein signatures, from all selected gel regions from nanoparticle bound cytosolic and nuclear proteins with $\mathrm{A}(2,4)$ scores above 300 are listed here. Note that the proteins tested by Western blots (Hsp90, TfRC and PARP) and alpha and beta actin are featured in this list (bold). 
Supplemental Table 1. Partial list of proteins adhering to dopamine-coated nanoparticles.

A(2,4) MS score; UniProtKB ; Gene ID; Species; Gene Name

13795.02 B2ZZ89 802976 Homo sapiens spectrin, beta, non-erythrocytic 1

11951.69 P06733 783039 Homo sapiens enolase 1, (alpha)

11488.63 P78527 791583 Homo sapiens similar to protein kinase, DNA-activated, catalytic polypeptide; protein kinase, DNA-activated, catalytic polypeptide

10943.35 Q09666 779036 Homo sapiens AHNAK nucleoprotein

9757.37 Q5SU16 800083 Homo sapiens tubulin, beta; similar to tubulin, beta 5; tubulin, beta pseudogene 2; tubulin, beta pseudogene 1

9642.91 Q6IPS9 821677 Homo sapiens eukaryotic translation elongation factor 1 alpha-like 7; eukaryotic translation elongation factor 1 alpha-like 3 ; similar to eukaryotic translation elongation factor 1 alpha 1 ; eukaryotic translation elongation factor 1 alpha 1

9588.70 Q9BQE3 823156 Homo sapiens tubulin, alpha 1c

9525.77 P68371 776899 Homo sapiens tubulin, beta 2C

8585.34 P68366 826978 Homo sapiens tubulin, alpha 4a

$8159.81 \quad$ Q13885 801263 Homo sapiens tubulin, beta 2A

$7639.81 \quad$ P13639 793126 Homo sapiens eukaryotic translation elongation factor 2

$6572.82 \quad$ P09651 824519 Homo sapiens heterogeneous nuclear ribonucleoprotein A1-like 3; similar to heterogeneous nuclear ribonucleoprotein A1; heterogeneous nuclear ribonucleoprotein A1 pseudogene 2; heterogeneous nuclear ribonucleoprotein $\mathrm{A} 1$; heterogeneous nuclear ribonucleoprotein $\mathrm{A} 1$ pseudogene

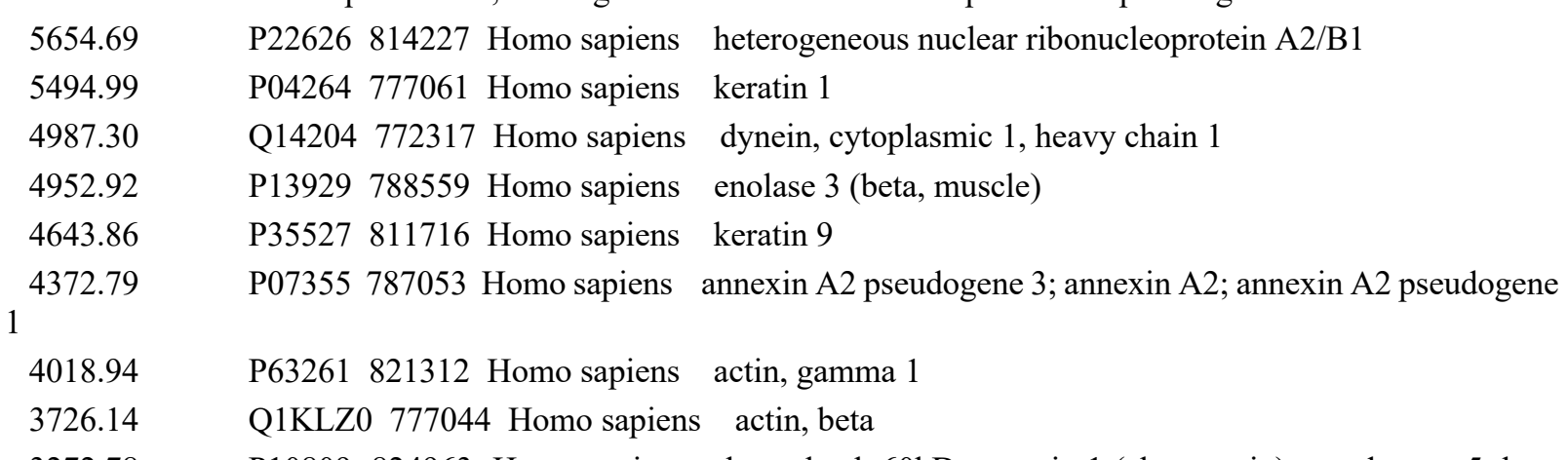

$3272.78 \quad$ P10809 824963 Homo sapiens heat shock 60kDa protein 1 (chaperonin) pseudogene 5; heat shock 60kDa protein 1 (chaperonin) pseudogene 6; heat shock 60kDa protein 1 (chaperonin) pseudogene 1; heat shock $60 \mathrm{kDa}$ protein 1 (chaperonin) pseudogene 4 ; heat shock $60 \mathrm{kDa}$ protein 1 (chaperonin)

2983.79 Q3ZCM7 809088 Homo sapiens tubulin, beta 8

$2619.12 \quad \mathrm{P} 13645822924$ Homo sapiens keratin 10

2500.62 Q6ZQN2 779036 Homo sapiens AHNAK nucleoprotein

2486.84 Q9BUF5 792713 Homo sapiens tubulin, beta 6

$2458.13 \quad$ P35908 799307 Homo sapiens keratin 2

$2393.35 \quad$ O15020 788928 Homo sapiens spectrin, beta, non-erythrocytic 2

2379.81 P50454 800499 Homo sapiens serpin peptidase inhibitor, clade H (heat shock protein 47), member 1, (collagen binding protein 1)

2205.17 P78371 819354 Homo sapiens chaperonin containing TCP1, subunit 2 (beta)

2062.57 P30101 791817 Homo sapiens protein disulfide isomerase family A, member 3

2055.22 Q5VTE0 821677 Homo sapiens eukaryotic translation elongation factor 1 alpha-like 7; eukaryotic translation elongation factor 1 alpha-like 3; similar to eukaryotic translation elongation factor 1 alpha 1; eukaryotic translation elongation factor 1 alpha 1

$2001.94 \quad$ O75369 778146 Homo sapiens filamin B, beta (actin binding protein 278)

1969.31 Q8WUM4 822885 Homo sapiens programmed cell death 6 interacting protein 
$1960.71 \quad$ P06748 810988 Homo sapiens nucleophosmin 1 (nucleolar phosphoprotein B23, numatrin) pseudogene 21; hypothetical LOC100131044; similar to nucleophosmin 1; nucleophosmin (nucleolar phosphoprotein B23, numatrin)

1873.25 Q16658 776911 Homo sapiens fascin homolog 1, actin-bundling protein (Strongylocentrotus purpuratus)

1867.63 Q5T6L4 783693 Homo sapiens argininosuccinate synthetase 1

1775.32 P07900 785761 Homo sapiens heat shock protein 90kDa alpha (cytosolic), class A member 2; heat shock protein $90 \mathrm{kDa}$ alpha (cytosolic), class A member 1

1753.73 P14625 804644 Homo sapiens heat shock protein 90kDa beta (Grp94), member 1

1753.42 Q53YD7 781923 Homo sapiens eukaryotic translation elongation factor 1 gamma

1634.74 A8K4W6 797595 Homo sapiens phosphoglycerate kinase 1

1615.92 P11586 784198 Homo sapiens methylenetetrahydrofolate dehydrogenase (NADP+ dependent) 1 , methenyltetrahydrofolate cyclohydrolase, formyltetrahydrofolate synthetase

1595.95 Q8TBA7 785761 Homo sapiens heat shock protein 90kDa alpha (cytosolic), class A member 2; heat shock protein $90 \mathrm{kDa}$ alpha (cytosolic), class A member 1

1563.98 Q9UQ80 774657 Homo sapiens proliferation-associated 2G4, 38kDa; proliferation-associated 2G4 pseudogene 4

$1563.02 \quad$ P02786 803569 Homo sapiens transferrin receptor (p90, CD71)

$1545.34 \quad$ P55060 776016 Homo sapiens CSE1 chromosome segregation 1-like (yeast)

$1458.93 \quad$ P68363 802675 Homo sapiens hypothetical gene supported by AF081484; NM_006082; tubulin, alpha $1 \mathrm{~b}$

1387.95 Q14103 799658 Homo sapiens heterogeneous nuclear ribonucleoprotein D (AU-rich element RNA binding protein $1,37 \mathrm{kDa})$

1303.14

Q9Y490 789529 Homo sapiens

talin 1

1302.96

P25705 786696 Homo sapiens

alpha subunit 1 , cardiac muscle

1300.16 P51991 810069 Homo sapiens heterogeneous nuclear ribonucleoprotein A3

1298.14 P19338 792174 Homo sapiens nucleolin

1283.27 P46940 817307 Homo sapiens IQ motif containing GTPase activating protein 1

1243.69 P61978 803294 Homo sapiens heterogeneous nuclear ribonucleoprotein K; similar to heterogeneous nuclear ribonucleoprotein $\mathrm{K}$

$1215.13 \quad$ P02538 776457 Homo sapiens keratin 6A

1209.31 Q53RC7 820046 Homo sapiens protein disulfide isomerase family A, member 6

1209.30 P00338 794884 Homo sapiens lactate dehydrogenase A

$1202.92 \quad$ P14618 774963 Homo sapiens similar to Pyruvate kinase, isozymes M1/M2 (Pyruvate kinase muscle isozyme) (Cytosolic thyroid hormone-binding protein) (CTHBP) (THBP1); pyruvate kinase, muscle

1192.50 Q9UBT2 824316 Homo sapiens ubiquitin-like modifier activating enzyme 2

1191.01 Q9NU22 792368 Homo sapiens MDN1, midasin homolog (yeast)

1175.06 Q13200793113 Homo sapiens proteasome (prosome, macropain) 26S subunit, non-ATPase,

2

1105.29 P08779 799223 Homo sapiens keratin 16; keratin type 16-like

1100.73 P04406 801768 Homo sapiens glyceraldehyde-3-phosphate dehydrogenase-like 6; hypothetical protein LOC100133042; glyceraldehyde-3-phosphate dehydrogenase

1049.66 P02533 787776 Homo sapiens keratin 14

$1048.19 \quad$ O43175 812627 Homo sapiens phosphoglycerate dehydrogenase

1047.78 Q5T081 775327 Homo sapiens regulator of chromosome condensation 1; SNHG3-RCC1 readthrough transcript

1036.83 P48735 782325 Homo sapiens isocitrate dehydrogenase 2 (NADP+), mitochondrial

$1036.01 \quad$ P32754 807953 Homo sapiens 4-hydroxyphenylpyruvate dioxygenase

1025.98 Q5TZP7 804284 Homo sapiens APEX nuclease (multifunctional DNA repair enzyme) 1 


\subsection{4 \\ 1001.55 \\ 999.69 \\ 975.71 \\ 954.66 \\ 931.47 \\ 930.96 \\ 913.26 \\ 912.91 \\ 910.75 \\ 896.88 sitive}

876.20

867.46

846.73

minoimid

839.87

830.23

822.19

821.74

814.61

813.00

homolog A (Xenopus laevis)

809.07 muted homolog (mouse)

797.16

P09622 793209 Homo sapiens

790.57

789.98

782.46

774.86

771.98 pseudogene

747.79

742.54

741.68

740.01

737.50

736.89

736.62

731.12

728.43

P62136 786351 Homo sapiens

P22695 788119 Homo sapiens

Q14974 798630 Homo sapiens

P49327 783505 Homo sapiens

A2RUM7 804383 Homo sapiens ribosomal protein L5

O43592 809951 Homo sapiens

to Exportin-T (tRNA exportin) (Exportin(tRNA))

710.83

699.42

691.02

685.42

subunit

674.03
Q16181 807411 Homo sapiens Q9UBB4 824796 Homo sapiens Q15293 782629 Homo sapiens P63010 777280 Homo sapiens Q9BY77 779076 Homo sapiens Q16881 816505 Homo sapiens Q01813 799578 Homo sapiens Q562R1 797358 Homo sapiens O43592 809951 Homo sapiens P35250 807483 Homo sapiens Q9BQG0 805661 Homo sapiens Q53TL5 776543 Homo sapiens Q96I99 812960 Homo sapiens lactate dehydrogenase B

$\mathrm{Tu}$ translation elongation factor, mitochondrial

aconitase 2 , mitochondrial

heterogeneous nuclear ribonucleoprotein A0

transformation/transcription domain-associated protein

serine/threonine kinase receptor associated protein

tubulin, alpha $3 \mathrm{~d}$; tubulin, alpha $3 \mathrm{c}$

heterogeneous nuclear ribonucleoprotein $\mathrm{H} 1(\mathrm{H})$

minichromosome maintenance complex component 6

methionyl-tRNA synthetase

hypothetical protein FLJ11822; aminopeptidase puromycin sen-

keratin 5

annexin A1

phosphoribosylaminoimidazole carboxylase, phosphoribosyla-

leucine aminopeptidase 3

thyroid hormone receptor interactor 13

fumarate hydratase

capping protein (actin filament), gelsolin-like

coatomer protein complex, subunit beta 1

protein phosphatase 1, catalytic subunit, beta isoform; speedy

thioredoxin domain containing 5 (endoplasmic reticulum);

dihydrolipoamide dehydrogenase

protein phosphatase 1, catalytic subunit, alpha isoform

ubiquinol-cytochrome $\mathrm{c}$ reductase core protein II

karyopherin (importin) beta 1

fatty acid synthase

ribosomal protein L5 pseudogene 34; ribosomal protein L5

septin 7

ataxin 10

reticulocalbin 1, EF-hand calcium binding domain

adaptor-related protein complex 2 , beta 1 subunit

polymerase (DNA-directed), delta interacting protein 3

thioredoxin reductase 1; hypothetical LOC100130902

phosphofructokinase, platelet

actin, beta-like 2

exportin, tRNA (nuclear export receptor for tRNAs); similar

replication factor $\mathrm{C}$ (activator 1) $2,40 \mathrm{kDa}$

MYB binding protein (P160) 1a

carbamoyl-phosphate synthetase 1, mitochondrial

similar to sucb; succinate-CoA ligase, GDP-forming, beta

eukaryotic translation initiation factor $4 \mathrm{~A}$, isoform 3 


\begin{tabular}{|c|c|}
\hline 673.72 & Q9P258 779514 Homo sapiens \\
\hline 670.97 & Q08J23 819340 Homo sapiens \\
\hline 669.99 & P42765 780710 Homo sapiens \\
\hline \multicolumn{2}{|r|}{$x$} \\
\hline 668.81 & P23921 795664 Homo sapiens \\
\hline 668.49 & A8K5J1 790254 Homo sapiens \\
\hline 666.90 & Q92769 814809 Homo sapiens \\
\hline 661.28 & P62195 808209 Homo sapiens \\
\hline 650.33 & Q9Y266 805698 Homo sapiens \\
\hline 643.56 & P06576 820161 Homo sapiens \\
\hline \multicolumn{2}{|c|}{ beta polypeptide } \\
\hline 635.08 & P08559 794862 Homo sapiens \\
\hline 633.49 & Q9H0C8 791191 Homo sapiens \\
\hline \multicolumn{2}{|r|}{ 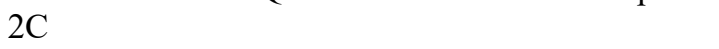 } \\
\hline 629.18 & P48643 801908 Homo sapiens \\
\hline 625.87 & Q10567 787777 Homo sapiens \\
\hline 617.34 & P45974 779174 Homo sapiens \\
\hline 617.19 & Q15019 793629 Homo sapiens \\
\hline 614.36 & P00505 795708 Homo sapiens \\
\hline
\end{tabular}

614.06

613.21

604.68

603.88

599.28

594.29

586.05

581.74

571.90

568.86

P38159 800702 Homo sapiens
; RNA binding motif protein, X-linked

$\begin{array}{ll}568.86 & \text { P38159 } 800702 \text { Homo sapiens } \\ \text { hCG2011544; RNA binding motif protein, X-linked }\end{array}$

560.75

i, pseudogene

558.97

557.82

553.27

P23396 816191 Homo sapiens

B2R4P8 796778 Homo sapiens

P24752 812798 Homo sapiens

P00390 827002 Homo sapiens

P11310 794504 Homo sapiens

P19013 783234 Homo sapiens

P29401 809989 Homo sapiens

O14929 822025 Homo sapiens

Q2Q9H2 772717 Homo sapiens

P78347 784409 Homo sapiens

Q6FHQ0 784316 Homo sapiens

P06737 804295 Homo sapiens

regulator of chromosome condensation 2

NOL1/NOP2/Sun domain family, member 2

hypothetical LOC648603; acetyl-Coenzyme A acyltransferase

ribonucleotide reductase $\mathrm{M} 1$

uridine monophosphate synthetase

histone deacetylase 2

proteasome (prosome, macropain) 26S subunit, ATPase, 5

nuclear distribution gene $\mathrm{C}$ homolog (A. nidulans)

ATP synthase, $\mathrm{H}+$ transporting, mitochondrial F1 complex,

pyruvate dehydrogenase (lipoamide) alpha 1

integrin-linked kinase-associated serine/threonine phosphatase

chaperonin containing TCP1, subunit 5 (epsilon)

adaptor-related protein complex 1, beta 1 subunit

ubiquitin specific peptidase 5 (isopeptidase T)

septin 2

glutamic-oxaloacetic transaminase 2, mitochondrial (aspartate

ribosomal protein S3 pseudogene 3; ribosomal protein S3

nascent polypeptide-associated complex alpha subunit

acetyl-Coenzyme A acetyltransferase 1

glutathione reductase

acyl-Coenzyme A dehydrogenase, C-4 to C-12 straight chain

keratin 4

transketolase

histone acetyltransferase 1

glucose-6-phosphate dehydrogenase

similar to RNA binding motif protein, X-linked; similar to

general transcription factor II, i; general transcription factor II, activated protein kinase kinase 2

552.88 Q16543 795814 Homo sapiens

544.89

P22314 801917 Homo sapiens

cell division cycle 37 homolog (S. cerevisiae)

539.24

P49736 803650 Homo sapiens

ubiquitin-like modifier activating enzyme 1

535.75

A4QPA9 811542 Homo sapiens mitogen-activated protein kinase kinase 1

535.09

P62333 777224 Homo sapiens proteasome (prosome, macropain) 26S subunit, ATPase, 6

533.01

B2R5T5 777762 Homo sapiens protein kinase, cAMP-dependent, regulatory, type I, alpha (tissue specific extinguisher 1)

532.15

O00231 823937 Homo sapiens proteasome (prosome, macropain) 26S subunit, non-ATPase,

11

528.85

P82979 789142 Homo sapiens SAP domain containing ribonucleoprotein

525.99

Q53GA7 823156 Homo sapiens tubulin, alpha 1c 


\subsection{1}

521.39

517.61

508.67

otide exch

\subsection{2}

502.00

ment factor $\mathrm{A}$ )

500.52

497.96

496.85

496.69

494.02

493.90

491.78

490.36

481.63

480.91

476.48

471.36

468.03 sion of tum

467.05

$52 \mathrm{kDa}$

465.03

464.94

456.78

alpha isoform

$35 \mathrm{kDa}$

454.54

448.33

441.52

440.46
454.89

O14980 804942 Homo sapiens

B2R6Q4 782032 Homo sapiens

A2ICT2 806387 Homo sapiens

P29692 813345 Homo sapiens

Q5T7Q0 816458 Homo sapiens

Q00839 817941 Homo sapiens

Q1W6H1 789155 Homo sapiens

Q8NC51 812365 Homo sapiens

P08238 807045 Homo sapiens

P11142 823976 Homo sapiens

Q9Y678 808517 Homo sapiens

P05455 781090 Homo sapiens

P14868 778056 Homo sapiens

O43684 792631 Homo sapiens

Q53SS8 798469 Homo sapiens

P55809 793880 Homo sapiens

Q8NFW8 789123 Homo sapiens

Q52LJ0 779142 Homo sapiens

Q2TU77 781245 Homo sapiens igenicity 13 (colon carcinoma) (Hsp70

P41091 776090 Homo sapiens

Q9ULV4 773825 Homo sapiens

Q99623 775357 Homo sapiens

exportin 1 (CRM1 homolog, yeast)

c-src tyrosine kinase

heat shock 70kDa protein 4-like

eukaryotic translation elongation factor 1 delta (guanine nucle-

DnaJ (Hsp40) homolog, subfamily A, member 1

heterogeneous nuclear ribonucleoprotein U (scaffold attach-

N-methylpurine-DNA glycosylase

SERPINE1 mRNA binding protein 1

heat shock protein $90 \mathrm{kDa}$ alpha (cytosolic), class B member 1

heat shock $70 \mathrm{kDa}$ protein 8

coatomer protein complex, subunit gamma

Sjogren syndrome antigen B (autoantigen La)

aspartyl-tRNA synthetase

budding uninhibited by benzimidazoles 3 homolog (yeast)

poly $(\mathrm{rC})$ binding protein 1

3-oxoacid CoA transferase 1

cytidine monophosphate $\mathrm{N}$-acetylneuraminic acid synthetase

family with sequence similarity 98 , member B

similar to heat shock $70 \mathrm{kD}$ protein binding protein; suppresinteracting protein)

eukaryotic translation initiation factor 2, subunit 3 gamma,

coronin, actin binding protein, $1 \mathrm{C}$

P63151 814637 Homo sapiens protein phosphatase 2 (formerly 2A), regulatory subunit B,

Q53XC0 815878 Homo sapiens eukaryotic translation initiation factor 2, subunit 1 alpha,

P26599 825901 Homo sapiens polypyrimidine tract binding protein 1

P35998 799755 Homo sapiens proteasome (prosome, macropain) 26S subunit, ATPase, 2

P31153 818352 Homo sapiens methionine adenosyltransferase II, alpha

sylglycinamide synthetase, phosphoribosylaminoimidazole synthetase

436.30

434.64

432.01

427.70

427.63

427.54

426.70

(Hu antigen R)

426.33

424.89

423.34

419.41

418.83
P22102 785682 Homo sapiens phosphoribosylglycinamide formyltransferase, phosphoribo-

P43490 799740 Homo sapiens nicotinamide phosphoribosyltransferase

Q32P51 813133 Homo sapiens heterogeneous nuclear ribonucleoprotein A1-like 2

Q9NR30 775290 Homo sapiens

Q9BQ52 776933 Homo sapiens

DEAD (Asp-Glu-Ala-Asp) box polypeptide 21

elaC homolog 2 (E. coli)

Q15233 776456 Homo sapiens

P49792 823753 Homo sapiens

Q15717 802485 Homo sapiens

non-POU domain containing, octamer-binding

RAN binding protein 2

ELAV (embryonic lethal, abnormal vision, Drosophila)-like 1

Q9P289 811390 Homo sapiens

Q14320 791498 Homo sapiens

P67809 788227 Homo sapiens

P50991 801999 Homo sapiens

O75821 792561 Homo sapiens

serine/threonine protein kinase MST4

family with sequence similarity 50 , member A

$\mathrm{Y}$ box binding protein 1

chaperonin containing TCP1, subunit 4 (delta)

eukaryotic translation initiation factor 3 , subunit $\mathrm{G}$ 
417.69

416.30

414.59

413.79

408.93

acid transport), member 2

408.13

406.76

406.00

401.13

399.42

397.69

397.09

CD29 incl

396.21

396.07

ribosomal

393.20

391.32

389.92

389.47

388.61

388.58

387.27

386.44

380.46

379.89

378.33

376.65

375.17

374.15

pseudogene 19; ribosomal protein L6; ribosomal pro

373.56

372.64

369.93 ribonucleoprotein $200 \mathrm{kDa}$ (U5)

367.23

360.47

359.98

357.99 system), member 5

357.06

354.78

349.00

348.36

343.18

342.62

Q6YN16 818917 Homo sapiens P02768 803627 Homo sapiens

Q86W42 820824 Homo sapiens O00154 806915 Homo sapiens P08195 781308 Homo sapiens

\section{P13646 772288 Homo sapiens} P27824 783822 Homo sapiens

Q9Y570 775081 Homo sapiens P52597 813541 Homo sapiens

P39023 802424 Homo sapiens rib Q9Y6E2 798384 Homo sapiens P05556 784977 Homo sapiens MDF2, MSK12)

Q6FHX6 798249 Homo sapiens

P36578 786754 Homo sapiens protein L4 pseudogene 4

$$
\text { P50213 } 786664 \text { Homo sapiens }
$$$$
\text { Q9H0S4 } 808234 \text { Homo sapiens }
$$$$
\text { Q13148 } 789485 \text { Homo sapiens }
$$$$
\text { Q9Y4G6 } 786177 \text { Homo sapiens }
$$$$
\text { Q5JVF3 } 780700 \text { Homo sapiens }
$$$$
\text { Q92785 } 811653 \text { Homo sapiens }
$$$$
\text { Q08945 } 824758 \text { Homo sapiens }
$$$$
\text { Q99986 } 807679 \text { Homo sapiens }
$$$$
\text { P07910 } 784420 \text { Homo sapiens }
$$$$
\text { Q5TGM6 } 799488 \text { Homo sapiens }
$$

$$
\text { P11717 } 789007 \text { Homo sapiens }
$$

$$
\text { O00442 } 802691 \text { Homo sapiens }
$$

A8K5I0 775531 Homo sapiens heat shock 70kDa protein 1A and 70kDa hsp 1B

hydroxysteroid dehydrogenase like 2

albumin

THO complex 6 homolog (Drosophila)

acyl-CoA thioesterase 7

solute carrier family 3 (activators of dibasic and neutral amino

keratin 13

calnexin

protein phosphatase methylesterase 1

heterogeneous nuclear ribonucleoprotein $\mathrm{F}$

bosomal protein L3; similar to 60S ribosomal protein L3 (L4)

basic leucine zipper and W2 domains 2

integrin, beta 1 (fibronectin receptor, beta polypeptide, antigen

flap structure-specific endonuclease 1

ribosomal protein L4; ribosomal protein L4 pseudogene 5;

isocitrate dehydrogenase $3(\mathrm{NAD}+)$ alpha

DEAD (Asp-Glu-Ala-Asp) box polypeptide 47

TAR DNA binding protein

talin 2

PCI domain containing 2

D4, zinc and double PHD fingers family 2

structure specific recognition protein 1

vaccinia related kinase 1

heterogeneous nuclear ribonucleoprotein $\mathrm{C}(\mathrm{C} 1 / \mathrm{C} 2)$

FK506 binding protein 5

insulin-like growth factor 2 receptor

RNA terminal phosphate cyclase domain 1

ribosomal protein L6 pseudogene 27; ribosomal protein L6 Q

ponent, homolog (S. cerevisiae) 
338.25 Q13155 797420 Homo sapiens tional protein 2; stromal antigen 3-like 3

336.07

335.13

334.68

333.18

333.04

329.66

324.63

321.41

321.01 shock $70 \mathrm{k}$

318.64

317.65

317.22

large, $\mathrm{PO}$

316.59

314.54

314.27

313.51

311.33

307.03

306.69

306.54

305.85

303.48 O95373 810275 Homo sapiens 000571797679 Homo sapiens P23526 796657 Homo sapiens P35249 778911 Homo sapiens Q96I65 803615 Homo sapiens aminoacyl tRNA synthetase complex-interacting multifuncgolgin B1, golgi integral membrane protein ATPase, $\mathrm{Na}+\mathrm{K}+$ transporting, alpha 1 polypeptide chromodomain helicase DNA binding protein 4 DEAD (Asp-Glu-Ala-Asp) box polypeptide 3, X-linked adenosylhomocysteinase replication factor $\mathrm{C}$ (activator 1) $4,37 \mathrm{kDa}$ eukaryotic translation initiation factor 4 gamma, 1 importin 7 hypothetical gene supported by AF216292; NM_005347; heat P11021 815675 Homo sapiens hypothe
ein 5 (glucose-regulated protein, 78kDa)

P56545 786688 Homo sapiens C-terminal binding protein 2

Q04637 803615 Homo sapiens eukaryotic translation initiation factor 4 gamma, 1

P05388 796227 Homo sapiens ribosomal protein, large, P0 pseudogene 2; ribosomal protein, gene 3; ribosomal protein, large, $\mathrm{P} 0$ pseudogene 6; ribosomal protein, large, $\mathrm{P} 0$

Q13813 803228 Homo sapiens spectrin, alpha, non-erythrocytic 1 (alpha-fodrin)

P36776 788157 Homo sapiens lon peptidase 1, mitochondrial

A2BF75 806428 Homo sapiens ATP-binding cassette, sub-family F (GCN20) member 1 P49454 793884 Homo sapiens centromere protein F, 350/400ka (mitosin)

Q15366 782567 Homo sapiens poly(rC) binding protein 2 P09874 806958 Homo sapiens poly (ADP-ribose) polymerase 1

P11216 779826 Homo sapiens phosphorylase, glycogen; brain P16615 782027 Homo sapiens ATPase, Ca++ transporting, cardiac muscle, slow twitch 2 O15160 790062 Homo sapiens polymerase (RNA) I polypeptide C, 30kDa P43246 812548 Homo sapiens mutS homolog 2, colon cancer, nonpolyposis type 1 (E. coli) 
Supplemental Table 2. The list of Annotation Clusters obtained by DAVID software analysis based on the list of proteins shown in Supplemental Table 1. A partial list of proteins from HeLa cell forming the corona on dopamine coated nanoparticles. Only clusters with enrichment scores above 1 are presented here.

\begin{tabular}{|c|c|c|c|}
\hline Annotation Cluster 1: Enrichment Score: 16.54 & Count & P_Value & Benjamini \\
\hline nucleotide binding & 114 & 7.80E-30 & $3.90 \mathrm{E}-27$ \\
\hline nucleotide-binding & 83 & $5.20 \mathrm{E}-28$ & $5.80 \mathrm{E}-26$ \\
\hline atp-binding & 64 & $1.30 \mathrm{E}-20$ & $9.00 \mathrm{E}-19$ \\
\hline purine nucleotide binding & 87 & $3.70 \mathrm{E}-18$ & 9.30E-16 \\
\hline purine ribonucleotide binding & 83 & 4.20E-17 & 7.10E-15 \\
\hline ribonucleotide binding & 83 & $4.20 \mathrm{E}-17$ & 7.10E-15 \\
\hline adenyl nucleotide binding & 71 & 4.10E-14 & 4.20E-12 \\
\hline purine nucleoside binding & 71 & $8.80 \mathrm{E}-14$ & 7.40E-12 \\
\hline nucleoside binding & 71 & $1.20 \mathrm{E}-13$ & $8.90 \mathrm{E}-12$ \\
\hline adenyl ribonucleotide binding & 67 & 4.10E-13 & $2.60 \mathrm{E}-11$ \\
\hline ATP binding & 66 & $7.10 \mathrm{E}-13$ & $4.00 \mathrm{E}-11$ \\
\hline nucleotide phosphate-binding region:ATP & 37 & $6.50 \mathrm{E}-09$ & 2.80E-06 \\
\hline Annotation Cluster 2: Enrichment Score: 13.07 & Count & P_Value & Benjamini \\
\hline membrane-enclosed lumen & 82 & $1.30 \mathrm{E}-17$ & $2.00 \mathrm{E}-15$ \\
\hline intracellular organelle lumen & 80 & $1.50 \mathrm{E}-17$ & $1.50 \mathrm{E}-15$ \\
\hline organelle lumen & 81 & $1.50 \mathrm{E}-17$ & $1.20 \mathrm{E}-15$ \\
\hline nuclear lumen & 57 & $1.10 \mathrm{E}-09$ & $3.70 \mathrm{E}-08$ \\
\hline nucleoplasm & 36 & $1.40 \mathrm{E}-06$ & 4.10E-05 \\
\hline Annotation Cluster 3: Enrichment Score: 10.02 & Count & $P_{-}$Value & Benjamini \\
\hline rna-binding & 43 & $2.10 \mathrm{E}-21$ & $1.70 \mathrm{E}-19$ \\
\hline RNA binding & 49 & $4.20 \mathrm{E}-16$ & $5.60 \mathrm{E}-14$ \\
\hline ribonucleoprotein complex & 40 & $1.30 \mathrm{E}-15$ & 8.30E-14 \\
\hline heterogeneous nuclear ribonucleoprotein complex & 11 & $2.50 \mathrm{E}-14$ & $1.30 \mathrm{E}-12$ \\
\hline ribonucleoprotein & 23 & $9.80 \mathrm{E}-12$ & 4.20E-10 \\
\hline RRM & 19 & $1.80 \mathrm{E}-11$ & $1.30 \mathrm{E}-09$ \\
\hline mrna splicing & 20 & $2.30 \mathrm{E}-11$ & $8.60 \mathrm{E}-10$ \\
\hline domain:RRM 1 & 14 & $5.20 \mathrm{E}-10$ & 4.60E-07 \\
\hline domain:RRM 2 & 14 & $5.20 \mathrm{E}-10$ & 4.60E-07 \\
\hline mrna processing & 20 & $9.70 \mathrm{E}-10$ & 2.30E-08 \\
\hline mRNA metabolic process & 27 & $1.00 \mathrm{E}-09$ & 7.70E-07 \\
\hline nuclear mRNA splicing, via spliceosome & 18 & $1.00 \mathrm{E}-09$ & $5.10 \mathrm{E}-07$ \\
\hline $\begin{array}{l}\text { RNA splicing, via transesterification reactions wi } \\
\text { ulged adenosine as nucleophile }\end{array}$ & 18 & $1.00 \mathrm{E}-09$ & $5.10 \mathrm{E}-07$ \\
\hline RNA splicing, via transesterification reactions & 18 & $1.00 \mathrm{E}-09$ & $5.10 \mathrm{E}-07$ \\
\hline RNA recognition motif, RNP-1 & 19 & 1.70E-09 & 2.60E-07 \\
\hline Nucleotide-binding, alpha-beta plait & 19 & $2.00 \mathrm{E}-09$ & $2.40 \mathrm{E}-07$ \\
\hline
\end{tabular}


RNA splicing

Spliceosome

RNA processing

mRNA processing

spliceosome

Spliceosome

Annotation Cluster 4: Enrichment Score: 9.36

non-membrane-bounded organelle

intracellular non-membrane-bounded organelle

cytoskeleton

Annotation Cluster 5: Enrichment Score: 7.99

heterogeneous nuclear ribonucleoprotein complex

methylation

domain:RRM 1

domain:RRM 2

PIRSF002072:helix-destabilizing protein

compositionally biased region:Gly-rich

domain:RRM 3

Annotation Cluster 6: Enrichment Score: 7.62

ATPase activity

AAA

ATPase, AAA + type, core

ATPase activity, coupled

Annotation Cluster 7: Enrichment Score: 7.31

melanosome

pigment granule

cytoplasmic membrane-bounded vesicle

membrane-bounded vesicle

vesicle

cytoplasmic vesicle

Annotation Cluster 8: Enrichment Score: 6.78

isopeptide bond

ubl conjugation

cross-link:Glycyl lysine isopeptide (Lys-Gly) (interchain with G-Cter in ubiquitin)

Annotation Cluster 9: Enrichment Score: 6.06

protein biosynthesis
3.60E-09

1.30E-06

$4.20 \mathrm{E}-09$

$9.50 \mathrm{E}-08$

$1.70 \mathrm{E}-08$

$5.00 \mathrm{E}-06$

3. $40 \mathrm{E}-08$

7.10E-06

$9.80 \mathrm{E}-06$

3.10E-07

$2.80 \mathrm{E}-03$

8.90E-05

P_Value

Benjamini

8.20E-11

8.20E-11

3.60E-04

$1.80 \mathrm{E}-05$

P_Value

Benjamini

1.30E-12

8.90E-09

4.60E-07

4.60E-07

4.90E-05

2.10E-04

1.00E-01

3.80E-03

Benjamini

3.40E-08

2.60E-07

$1.70 \mathrm{E}-05$

$1.70 \mathrm{E}-07$

$1.10 \mathrm{E}-05$

$3.00 \mathrm{E}-07$

Benjamini

3.90E-12

3.90E-12

3.50E-04

4.90E-04

2.80E-05

8.90E-04

1.10E-03

7.30E-05

Benjamini

1.00E-07

7.90E-06

$5.20 \mathrm{E}-07$

1.90E-04

1.80E-06

Benjamini

8.20E-09 
translation

translational elongation

translation factor activity, nucleic acid binding

Annotation Cluster 10: Enrichment Score: 6.03

Chaperone

unfolded protein binding

molecular chaperone

protein folding

stress response

response to unfolded protein

response to protein stimulus

Antigen processing and presentation

Annotation Cluster 11: Enrichment Score: 5.82

generation of precursor metabolites and energy

cellular carbohydrate catabolic process

glycolysis

carbohydrate catabolic process

glucose metabolic process

glucose catabolic process

glycolysis

hexose catabolic process

monosaccharide catabolic process

hexose metabolic process

alcohol catabolic process

Glycolysis / Gluconeogenesis

monosaccharide metabolic process

binding site:Substrate

Pyruvate metabolism

Annotation Cluster 12: Enrichment Score: 5.39

structural molecule activity

cytoskeleton

cytoskeletal part

microtubule cytoskeleton

Annotation Cluster 13: Enrichment Score: 5.18

Tubulin/FtsZ, 2-layer sandwich domain

Tubulin, conserved site

Tubulin/FtsZ, GTPase domain

Tubulin

PIRSF002306:tubulin

\section{Count}

4.40E-06

3.20E-04

8.90E-06

5.30E-04

$5.30 \mathrm{E}-05$

$1.40 \mathrm{E}-03$

Benjamini

7.30E-12

$6.40 \mathrm{E}-10$

$6.00 \mathrm{E}-06$

$5.20 \mathrm{E}-05$

$1.60 \mathrm{E}-03$

$8.30 \mathrm{E}-03$

$5.30 \mathrm{E}-02$

$2.10 \mathrm{E}-01$

$2.00 \mathrm{E}-02$

P_Value

Benjamini

2.30E-07

5.20E-06

$1.30 \mathrm{E}-06$

$5.80 \mathrm{E}-05$

$5.50 \mathrm{E}-05$

$6.90 \mathrm{E}-05$

$1.30 \mathrm{E}-04$

2.40E-04

$2.70 \mathrm{E}-04$

4.00E-04

$5.40 \mathrm{E}-04$

8.20E-04

$1.40 \mathrm{E}-03$

$2.20 \mathrm{E}-03$

$5.30 \mathrm{E}-02$

$3.50 \mathrm{E}-03$

Benjamini

1.40E-08

3.60E-04

3.70E-04

$2.50 \mathrm{E}-02$

$2.20 \mathrm{E}-03$

Benjamini

2.70E-07

2.00E-07

$2.00 \mathrm{E}-07$

2.00E-07

2.10E-06 


\begin{tabular}{|c|c|c|c|}
\hline Pathogenic Escherichia coli infection & 13 & $1.50 \mathrm{E}-08$ & $1.90 \mathrm{E}-06$ \\
\hline cellular protein complex assembly & 16 & $1.20 \mathrm{E}-07$ & $2.20 \mathrm{E}-05$ \\
\hline protein polymerization & 9 & $1.60 \mathrm{E}-06$ & $1.70 \mathrm{E}-04$ \\
\hline protein complex assembly & 26 & $1.90 \mathrm{E}-06$ & $1.90 \mathrm{E}-04$ \\
\hline protein complex biogenesis & 26 & $1.90 \mathrm{E}-06$ & $1.90 \mathrm{E}-04$ \\
\hline gtp-binding & 17 & $5.10 \mathrm{E}-06$ & $6.30 \mathrm{E}-05$ \\
\hline nucleotide phosphate-binding region:GTP & 16 & $6.30 \mathrm{E}-06$ & $5.00 \mathrm{E}-04$ \\
\hline cellular macromolecular complex assembly & 19 & $9.50 \mathrm{E}-06$ & $5.40 \mathrm{E}-04$ \\
\hline Beta tubulin & 5 & $1.30 \mathrm{E}-05$ & $7.70 \mathrm{E}-04$ \\
\hline Gap junction & 12 & $1.50 \mathrm{E}-05$ & $9.70 \mathrm{E}-04$ \\
\hline microtubule-based movement & 11 & $2.40 \mathrm{E}-05$ & $1.30 \mathrm{E}-03$ \\
\hline macromolecular complex assembly & 28 & $2.80 \mathrm{E}-05$ & $1.40 \mathrm{E}-03$ \\
\hline $\begin{array}{l}\text { cellular macromolecular complex subunit organiza- } \\
\text { tion }\end{array}$ & 19 & 4.40E-05 & $2.10 \mathrm{E}-03$ \\
\hline macromolecular complex subunit organization & 28 & $8.60 \mathrm{E}-05$ & $3.70 \mathrm{E}-03$ \\
\hline GTPase activity & 14 & $8.70 \mathrm{E}-05$ & $2.10 \mathrm{E}-03$ \\
\hline Beta tubulin, autoregulation binding site & 5 & $1.10 \mathrm{E}-04$ & $5.00 \mathrm{E}-03$ \\
\hline microtubule & 12 & $1.90 \mathrm{E}-04$ & $1.60 \mathrm{E}-03$ \\
\hline GTP binding & 7 & $2.00 \mathrm{E}-04$ & $1.70 \mathrm{E}-03$ \\
\hline Alpha tubulin & 4 & $2.40 \mathrm{E}-04$ & $9.20 \mathrm{E}-03$ \\
\hline GTP binding & 17 & $8.60 \mathrm{E}-04$ & $1.50 \mathrm{E}-02$ \\
\hline guanyl ribonucleotide binding & 17 & $1.10 \mathrm{E}-03$ & $1.90 \mathrm{E}-02$ \\
\hline guanyl nucleotide binding & 17 & $1.10 \mathrm{E}-03$ & $1.90 \mathrm{E}-02$ \\
\hline microtubule-based process & 13 & $1.40 \mathrm{E}-03$ & $3.60 \mathrm{E}-02$ \\
\hline microtubule cytoskeleton & 20 & $2.20 \mathrm{E}-03$ & $2.50 \mathrm{E}-02$ \\
\hline microtubule & 13 & $2.30 \mathrm{E}-03$ & $2.50 \mathrm{E}-02$ \\
\hline Annotation Cluster 14: Enrichment Score: 4.2 & Count & $P_{-}$Value & Benjamini \\
\hline nucleocytoplasmic transport & 14 & $2.80 \mathrm{E}-06$ & $2.50 \mathrm{E}-04$ \\
\hline nuclear transport & 14 & $3.30 \mathrm{E}-06$ & $2.50 \mathrm{E}-04$ \\
\hline nucleic acid transport & 11 & $6.20 \mathrm{E}-06$ & $4.20 \mathrm{E}-04$ \\
\hline RNA transport & 11 & $6.20 \mathrm{E}-06$ & $4.20 \mathrm{E}-04$ \\
\hline establishment of RNA localization & 11 & $6.20 \mathrm{E}-06$ & $4.20 \mathrm{E}-04$ \\
\hline RNA localization & 11 & $8.10 \mathrm{E}-06$ & $5.00 \mathrm{E}-04$ \\
\hline $\begin{array}{l}\text { nucleobase, nucleoside, nucleotide and nucleic acid } \\
\text { transport }\end{array}$ & 11 & $2.40 \mathrm{E}-05$ & $1.30 \mathrm{E}-03$ \\
\hline mRNA transport & 7 & $3.50 \mathrm{E}-04$ & $2.60 \mathrm{E}-03$ \\
\hline nuclear export & 7 & $5.50 \mathrm{E}-04$ & $1.80 \mathrm{E}-02$ \\
\hline RNA export from nucleus & 6 & $6.40 \mathrm{E}-04$ & $2.00 \mathrm{E}-02$ \\
\hline mRNA transport & 8 & $7.30 \mathrm{E}-04$ & $2.10 \mathrm{E}-02$ \\
\hline mRNA export from nucleus & 3 & $1.10 \mathrm{E}-01$ & $6.10 \mathrm{E}-01$ \\
\hline Annotation Cluster 15: Enrichment Score: 4.11 & Count & $P_{-}$Value & Benjamini \\
\hline structural constituent of cytoskeleton & 16 & $2.00 \mathrm{E}-12$ & $1.00 \mathrm{E}-10$ \\
\hline
\end{tabular}




\begin{tabular}{|c|c|c|c|}
\hline region of interest:Coil 2 & 10 & $1.20 \mathrm{E}-07$ & $3.40 \mathrm{E}-05$ \\
\hline region of interest:Linker 12 & 10 & $1.20 \mathrm{E}-07$ & 3.40E-05 \\
\hline region of interest:Coil 1B & 10 & $2.60 \mathrm{E}-07$ & $5.60 \mathrm{E}-05$ \\
\hline region of interest:Coil 1A & 10 & $2.60 \mathrm{E}-07$ & $5.60 \mathrm{E}-05$ \\
\hline region of interest:Linker 1 & 10 & 2.60E-07 & $5.60 \mathrm{E}-05$ \\
\hline region of interest:Rod & 10 & 2.90E-07 & 5.10E-05 \\
\hline region of interest:Head & 10 & 3.70E-07 & $5.40 \mathrm{E}-05$ \\
\hline region of interest:Tail & 10 & 4.70E-07 & 5.90E-05 \\
\hline Intermediate filament & 10 & $6.30 \mathrm{E}-07$ & $9.20 \mathrm{E}-06$ \\
\hline PIRSF002282:cytoskeletal keratin & 10 & 7.80E-06 & $3.90 \mathrm{E}-04$ \\
\hline Filament & 9 & $9.20 \mathrm{E}-06$ & $6.80 \mathrm{E}-04$ \\
\hline Intermediate filament protein, conserved site & 9 & $9.20 \mathrm{E}-06$ & $6.80 \mathrm{E}-04$ \\
\hline Intermediate filament protein & 9 & $1.00 \mathrm{E}-05$ & $6.70 \mathrm{E}-04$ \\
\hline site:Stutter & 6 & 5.80E-05 & 3.60E-03 \\
\hline palmoplantar keratoderma & 5 & $8.40 \mathrm{E}-05$ & 8.90E-04 \\
\hline keratin & 10 & $9.40 \mathrm{E}-05$ & $9.70 \mathrm{E}-04$ \\
\hline ectoderm development & 12 & $6.50 \mathrm{E}-04$ & $2.00 \mathrm{E}-02$ \\
\hline keratin filament & 8 & $6.70 \mathrm{E}-04$ & $9.00 \mathrm{E}-03$ \\
\hline Keratin, type I & 5 & $1.30 \mathrm{E}-03$ & $3.00 \mathrm{E}-02$ \\
\hline epidermis development & 11 & $1.30 \mathrm{E}-03$ & 3.30E-02 \\
\hline intermediate filament & 10 & $3.70 \mathrm{E}-03$ & $3.50 \mathrm{E}-02$ \\
\hline intermediate filament cytoskeleton & 10 & 4.30E-03 & 3.90E-02 \\
\hline Type II keratin & 4 & $7.50 \mathrm{E}-03$ & $1.30 \mathrm{E}-01$ \\
\hline intermediate filament cytoskeleton organization & 3 & 4.50E-02 & 4.00E-01 \\
\hline intermediate filament-based process & 3 & $5.40 \mathrm{E}-02$ & 4.30E-01 \\
\hline epithelial cell differentiation & 6 & 8.70E-02 & $5.50 \mathrm{E}-01$ \\
\hline keratinocyte differentiation & 3 & $3.10 \mathrm{E}-01$ & 8.90E-01 \\
\hline epithelium development & 6 & $3.50 \mathrm{E}-01$ & $9.10 \mathrm{E}-01$ \\
\hline epidermal cell differentiation & 3 & $3.50 \mathrm{E}-01$ & $9.10 \mathrm{E}-01$ \\
\hline coiled coil & 21 & $9.00 \mathrm{E}-01$ & $1.00 \mathrm{E}+00$ \\
\hline Annotation Cluster 16: Enrichment Score: 3.88 & Count & P_Value & Benjamini \\
\hline Chaperone, tailless complex polypeptide 1 & 5 & $1.30 \mathrm{E}-05$ & 7.70E-04 \\
\hline Chaperonin Cpn60/TCP-1 & 5 & $5.10 \mathrm{E}-05$ & $2.70 \mathrm{E}-03$ \\
\hline chaperonin-containing T-complex & 4 & $1.50 \mathrm{E}-04$ & $2.20 \mathrm{E}-03$ \\
\hline Chaperonin TCP-1, conserved site & 4 & 3.30E-04 & $1.10 \mathrm{E}-02$ \\
\hline PIRSF002584:molecular chaperone t-complex-type & 4 & $1.20 \mathrm{E}-03$ & $3.60 \mathrm{E}-02$ \\
\hline Annotation Cluster 17: Enrichment Score: 3.73 & Count & P_Value & Benjamini \\
\hline cofactor binding & 18 & $1.80 \mathrm{E}-06$ & $6.00 \mathrm{E}-05$ \\
\hline NAD or NADH binding & 8 & $1.60 \mathrm{E}-05$ & 4.70E-04 \\
\hline NAD(P)-binding domain & 11 & $6.60 \mathrm{E}-05$ & $3.20 \mathrm{E}-03$ \\
\hline coenzyme binding & 13 & $8.10 \mathrm{E}-05$ & $2.00 \mathrm{E}-03$ \\
\hline
\end{tabular}




\begin{tabular}{|c|c|c|c|}
\hline nad & 11 & $1.60 \mathrm{E}-04$ & $1.40 \mathrm{E}-03$ \\
\hline oxidoreductase & 19 & $3.20 \mathrm{E}-04$ & $2.50 \mathrm{E}-03$ \\
\hline binding site:NAD & 6 & 4.30E-04 & $1.90 \mathrm{E}-02$ \\
\hline nucleotide phosphate-binding region:NAD & 6 & $2.90 \mathrm{E}-03$ & 8.90E-02 \\
\hline oxidation reduction & 19 & $2.70 \mathrm{E}-02$ & 2.90E-01 \\
\hline Annotation Cluster 18: Enrichment Score: 3.28 & Count & P_Value & Benjamini \\
\hline energy derivation by oxidation of organic compounds & 13 & $6.90 \mathrm{E}-06$ & $4.40 \mathrm{E}-04$ \\
\hline Citrate cycle (TCA cycle) & 7 & $1.20 \mathrm{E}-04$ & $2.90 \mathrm{E}-03$ \\
\hline tricarboxylic acid cycle & 5 & $1.30 \mathrm{E}-04$ & $1.20 \mathrm{E}-03$ \\
\hline acetyl-CoA metabolic process & 6 & $1.70 \mathrm{E}-04$ & $6.90 \mathrm{E}-03$ \\
\hline aerobic respiration & 6 & $3.00 \mathrm{E}-04$ & $1.20 \mathrm{E}-02$ \\
\hline coenzyme metabolic process & 11 & $3.10 \mathrm{E}-04$ & $1.20 \mathrm{E}-02$ \\
\hline acetyl-CoA catabolic process & 5 & $5.80 \mathrm{E}-04$ & $1.90 \mathrm{E}-02$ \\
\hline tricarboxylic acid cycle & 5 & $5.80 \mathrm{E}-04$ & $1.90 \mathrm{E}-02$ \\
\hline coenzyme catabolic process & 5 & $9.40 \mathrm{E}-04$ & 2.60E-02 \\
\hline cofactor catabolic process & 5 & $1.80 \mathrm{E}-03$ & 4.30E-02 \\
\hline cofactor metabolic process & 11 & $2.00 \mathrm{E}-03$ & 4.50E-02 \\
\hline cellular respiration & 7 & $6.40 \mathrm{E}-03$ & $1.10 \mathrm{E}-01$ \\
\hline dicarboxylic acid metabolic process & 4 & $2.00 \mathrm{E}-02$ & 2.30E-01 \\
\hline Annotation Cluster 19: Enrichment Score: 3.26 & Count & $P_{-}$Value & Benjamini \\
\hline translation factor activity, nucleic acid binding & 10 & 5.30E-05 & $1.40 \mathrm{E}-03$ \\
\hline elongation factor & 5 & $1.30 \mathrm{E}-04$ & $1.20 \mathrm{E}-03$ \\
\hline translation elongation factor activity & 5 & 7.30E-04 & $1.40 \mathrm{E}-02$ \\
\hline Translation elongation factor EFTu/EF1A, domain 2 & 4 & $1.20 \mathrm{E}-03$ & $3.00 \mathrm{E}-02$ \\
\hline Protein synthesis factor, GTP-binding & 4 & $1.80 \mathrm{E}-03$ & 4.00E-02 \\
\hline eukaryotic translation elongation factor 1 complex & 3 & $2.70 \mathrm{E}-03$ & $2.80 \mathrm{E}-02$ \\
\hline Annotation Cluster 20: Enrichment Score: 2.98 & Count & P_Value & Benjamini \\
\hline regulation of mRNA stability & 5 & 4.80E-04 & $1.70 \mathrm{E}-02$ \\
\hline regulation of RNA stability & 5 & $6.80 \mathrm{E}-04$ & $2.10 \mathrm{E}-02$ \\
\hline RNA stabilization & 4 & $1.90 \mathrm{E}-03$ & 4.50E-02 \\
\hline mRNA stabilization & 4 & $1.90 \mathrm{E}-03$ & 4.50E-02 \\
\hline Annotation Cluster 21: Enrichment Score: 2.93 & Count & P_Value & Benjamini \\
\hline dna replication & 9 & $1.60 \mathrm{E}-05$ & $1.90 \mathrm{E}-04$ \\
\hline $\begin{array}{l}\text { PIRSF004274:phage T4 DNA polymerase accessory } \\
\text { rotein } 44\end{array}$ & 4 & $4.40 \mathrm{E}-05$ & $1.70 \mathrm{E}-03$ \\
\hline DNA clamp loader activity & 4 & $5.10 \mathrm{E}-05$ & $1.40 \mathrm{E}-03$ \\
\hline protein-DNA loading ATPase activity & 4 & $5.10 \mathrm{E}-05$ & $1.40 \mathrm{E}-03$ \\
\hline DNA replication factor $\mathrm{C}$ complex & 4 & $8.90 \mathrm{E}-05$ & $1.30 \mathrm{E}-03$ \\
\hline DNA replication & 7 & $2.80 \mathrm{E}-04$ & $5.80 \mathrm{E}-03$ \\
\hline
\end{tabular}




\begin{tabular}{|c|c|c|c|}
\hline Replication factor $\mathrm{C}$ & 3 & $6.20 \mathrm{E}-04$ & $1.90 \mathrm{E}-02$ \\
\hline DNA replication & 11 & $1.60 \mathrm{E}-03$ & 4.00E-02 \\
\hline replication fork & 5 & $1.90 \mathrm{E}-03$ & 2.30E-02 \\
\hline Mismatch repair & 5 & $2.60 \mathrm{E}-03$ & 4.60E-02 \\
\hline DNA strand elongation during DNA replication & 3 & 2.80E-03 & $6.10 \mathrm{E}-02$ \\
\hline nucleotide-excision repair, DNA gap filling & 4 & 2.80E-03 & $6.00 \mathrm{E}-02$ \\
\hline DNA strand elongation & 3 & 4.20E-03 & 8.20E-02 \\
\hline DNA-dependent DNA replication & 5 & $1.70 \mathrm{E}-02$ & 2.10E-01 \\
\hline DNA-dependent ATPase activity & 5 & $1.70 \mathrm{E}-02$ & $2.00 \mathrm{E}-01$ \\
\hline nucleotide-excision repair & 4 & $6.80 \mathrm{E}-02$ & 4.90E-01 \\
\hline Nucleotide excision repair & 4 & $1.10 \mathrm{E}-01$ & $5.40 \mathrm{E}-01$ \\
\hline Annotation Cluster 22: Enrichment Score: 2.92 & Count & $\mathrm{P}_{-}$Value & Benjamini \\
\hline repeat: $1-2$ & 5 & $3.10 \mathrm{E}-04$ & $1.50 \mathrm{E}-02$ \\
\hline repeat: $1-1$ & 5 & $3.60 \mathrm{E}-04$ & $1.60 \mathrm{E}-02$ \\
\hline repeat:2-1 & 4 & $3.80 \mathrm{E}-03$ & $1.00 \mathrm{E}-01$ \\
\hline repeat:2-2 & 4 & 4.80E-03 & $1.20 \mathrm{E}-01$ \\
\hline Annotation Cluster 23: Enrichment Score: 2.88 & Count & $\mathrm{P}_{-}$Value & Benjamini \\
\hline ATPase activity, coupled & 20 & $3.00 \mathrm{E}-07$ & $1.10 \mathrm{E}-05$ \\
\hline short sequence motif:Q motif & 6 & $1.00 \mathrm{E}-04$ & $5.50 \mathrm{E}-03$ \\
\hline RNA helicase, DEAD-box type, Q motif & 6 & $1.80 \mathrm{E}-04$ & 7.60E-03 \\
\hline HELICc & 8 & $1.90 \mathrm{E}-04$ & 4.60E-03 \\
\hline DEXDc & 8 & $2.30 \mathrm{E}-04$ & 4.10E-03 \\
\hline $\begin{array}{l}\text { DNA/RNA helicase, DEAD/DEAH box type, } \mathrm{N}-\mathrm{t} \\
\text { minal }\end{array}$ & 7 & $2.50 \mathrm{E}-04$ & $9.00 \mathrm{E}-03$ \\
\hline ATP-dependent RNA helicase activity & 5 & 4.30E-04 & $8.70 \mathrm{E}-03$ \\
\hline RNA-dependent ATPase activity & 5 & $5.20 \mathrm{E}-04$ & $1.00 \mathrm{E}-02$ \\
\hline Helicase, superfamily 1 and 2, ATP-binding & 8 & $9.30 \mathrm{E}-04$ & $2.70 \mathrm{E}-02$ \\
\hline DNA/RNA helicase, C-terminal & 8 & 9.30E-04 & 2.70E-02 \\
\hline DEAD-like helicase, N-terminal & 8 & $1.00 \mathrm{E}-03$ & $2.70 \mathrm{E}-02$ \\
\hline RNA helicase activity & 5 & $1.50 \mathrm{E}-03$ & $2.50 \mathrm{E}-02$ \\
\hline helicase & 8 & $1.60 \mathrm{E}-03$ & $1.10 \mathrm{E}-02$ \\
\hline purine NTP-dependent helicase activity & 8 & $1.60 \mathrm{E}-03$ & $2.60 \mathrm{E}-02$ \\
\hline ATP-dependent helicase activity & 8 & $1.60 \mathrm{E}-03$ & $2.60 \mathrm{E}-02$ \\
\hline domain:Helicase C-terminal & 7 & $2.30 \mathrm{E}-03$ & 7.70E-02 \\
\hline domain:Helicase ATP-binding & 7 & 2.90E-03 & 8.60E-02 \\
\hline helicase activity & 9 & $3.20 \mathrm{E}-03$ & 4.60E-02 \\
\hline PIRSF003023:translation initiation factor eIF-4A & 3 & $4.80 \mathrm{E}-03$ & $1.20 \mathrm{E}-01$ \\
\hline $\begin{array}{l}\text { RNA helicase, ATP-dependent, DEAD-box, cc } \\
\text { erved site }\end{array}$ & 4 & $1.10 \mathrm{E}-02$ & $1.70 \mathrm{E}-01$ \\
\hline short sequence motif:DEAD box & 3 & $6.60 \mathrm{E}-02$ & $6.90 \mathrm{E}-01$ \\
\hline nuclear speck & 4 & $2.50 \mathrm{E}-01$ & $6.80 \mathrm{E}-01$ \\
\hline
\end{tabular}


Annotation Cluster 24: Enrichment Score: 2.49

Count

cell cortex

cell cortex part

cytoskeleton

Annotation Cluster 25: Enrichment Score: 2.39

cytosolic part

translational elongation

ribosome

cytosolic large ribosomal subunit

large ribosomal subunit

cytosolic ribosome

ribosomal subunit

ribosome

Ribosome

ribosomal protein

structural constituent of ribosome

Annotation Cluster 26: Enrichment Score: 2.38

mitochondrial matrix

mitochondrial lumen

transit peptide

transit peptide:Mitochondrion

Citrate cycle (TCA cycle)

mitochondrion

mitochondrial part

mitochondrion

organelle envelope

envelope

mitochondrial inner membrane

organelle inner membrane

mitochondrial membrane

mitochondrial envelope

organelle membrane

Annotation Cluster 27: Enrichment Score: 2.32

cell cycle

mitotic cell cycle

cell cycle process

mitosis

mitosis
10

7

16

Count

14

11

6

5

6

6

7

9

6

6

6

\section{Count}

16

16

20

19

7

22

19

28

18

18

9

9

9

9

19

Count

30

19

24

10

11
$\mathrm{P}$ Value

7.80E-04

2.70E-03

$1.60 \mathrm{E}-02$

$\mathrm{P}_{-}$Value

$1.60 \mathrm{E}-06$

8.90E-06

2.30E-03

3.60E-03

5.20E-03

$1.20 \mathrm{E}-02$

2.10E-02

2.80E-02

7.50E-02

9.20E-02

1.70E-01

P_Value

6.40E-06

6.40E-06

$1.10 \mathrm{E}-05$

3.40E-05

$1.20 \mathrm{E}-04$

2.20E-03

$1.10 \mathrm{E}-02$

2.50E-02

3.10E-02

3.20E-02

1.40E-01

1.90E-01

3.40E-01

4.00E-01

5.70E-01

P_Value

6.30E-05

7.00E-05

1.10E-04

5.60E-04

4.70E-03
Benjamini

1.00E-02

2.80E-02

$6.90 \mathrm{E}-02$

Benjamini

4.10E-05

5.30E-04

$1.50 \mathrm{E}-02$

3.60E-02

4.70E-02

8.40E-02

1.30E-01

$1.60 \mathrm{E}-01$

4.30E-01

3.00E-01

7.70E-01

Benjamini

1.40E-04

1.40E-04

$1.40 \mathrm{E}-04$

$2.30 \mathrm{E}-03$

2.90E-03

1.40E-02

8.30E-02

1.40E-01

1.60E-01

1.70E-01

5.10E-01

6.00E-01

$7.80 \mathrm{E}-01$

8.40E-01

9.30E-01

Benjamini

2.90E-03

3.10E-03

4.60E-03

4.10E-03

$9.00 \mathrm{E}-02$ 
nuclear division

M phase of mitotic cell cycle

organelle fission

cell division

M phase

cell cycle phase

cell cycle

cell division

chromosome, centromeric region

spindle

Annotation Cluster 28: Enrichment Score: 2.29

allosteric enzyme

energy reserve metabolic process

cellular polysaccharide metabolic process

glycogen metabolism

glycogen metabolic process

glucan metabolic process

cellular glucan metabolic process

glycogen catabolic process

cellular polysaccharide catabolic process

glucan catabolic process

carbohydrate metabolism

polysaccharide metabolic process

Insulin signaling pathway

polysaccharide catabolic process

Annotation Cluster 29: Enrichment Score: 2.29

translation factor activity, nucleic acid binding

Initiation factor

translation initiation factor activity

Annotation Cluster 30: Enrichment Score: 2.28

short sequence motif:Prevents secretion from ER

Redox-active center

Endoplasmic reticulum, targeting sequence

cell redox homeostasis

endoplasmic reticulum lumen

Disulphide isomerase

domain:Thioredoxin 2

domain:Thioredoxin 1

Thioredoxin-like subdomain

PIRSF001487:protein disulfide-isomerase
Count

6

Count

10

4

4

Count

7

6

6

7

4.70E-03

$5.30 \mathrm{E}-03$

$6.20 \mathrm{E}-03$

$6.70 \mathrm{E}-03$

$1.10 \mathrm{E}-02$

$1.20 \mathrm{E}-02$

$1.50 \mathrm{E}-02$

$1.40 \mathrm{E}-01$

$1.50 \mathrm{E}-01$

$2.30 \mathrm{E}-01$

P Value

1.30E-04

$8.00 \mathrm{E}-04$

$2.10 \mathrm{E}-03$

$2.60 \mathrm{E}-03$

$2.90 \mathrm{E}-03$

$3.20 \mathrm{E}-03$

$3.20 \mathrm{E}-03$

$4.20 \mathrm{E}-03$

$5.80 \mathrm{E}-03$

$5.80 \mathrm{E}-03$

$1.60 \mathrm{E}-02$

$4.20 \mathrm{E}-02$

$6.10 \mathrm{E}-02$

$8.30 \mathrm{E}-02$

P Value

5.30E-05

$2.80 \mathrm{E}-02$

$9.10 \mathrm{E}-02$

P_Value

1.00E-04

$1.80 \mathrm{E}-04$

$4.60 \mathrm{E}-04$

$7.20 \mathrm{E}-04$

$2.20 \mathrm{E}-03$

$3.00 \mathrm{E}-03$

$5.50 \mathrm{E}-03$

$5.50 \mathrm{E}-03$

8.70E-03

$9.90 \mathrm{E}-03$
$9.00 \mathrm{E}-02$

$9.40 \mathrm{E}-02$

$1.00 \mathrm{E}-01$

3.70E-02

1.60E-01

$1.60 \mathrm{E}-01$

6.70E-02

6.70E-01

$5.30 \mathrm{E}-01$

$6.60 \mathrm{E}-01$

Benjamini

1.20E-03

2.30E-02

4.60E-02

$1.60 \mathrm{E}-02$

$6.00 \mathrm{E}-02$

$6.60 \mathrm{E}-02$

6.60E-02

$8.20 \mathrm{E}-02$

9.90E-02

9.90E-02

7.00E-02

$3.80 \mathrm{E}-01$

4.10E-01

$5.40 \mathrm{E}-01$

Benjamini

1.40E-03

$1.10 \mathrm{E}-01$

$5.90 \mathrm{E}-01$

Benjamini

5.30E-03

$1.60 \mathrm{E}-03$

$1.50 \mathrm{E}-02$

2.10E-02

2.60E-02

6.10E-02

$1.40 \mathrm{E}-01$

$1.40 \mathrm{E}-01$

$1.40 \mathrm{E}-01$

$1.90 \mathrm{E}-01$ 
ER-Golgi intermediate compartment

Thioredoxin, conserved site

Thioredoxin domain

Thioredoxin fold

Thioredoxin-like

Annotation Cluster 31: Enrichment Score: 2.18

DNA metabolic process

cellular response to stress

DNA repair

response to DNA damage stimulus

dna repair

DNA damage

base-excision repair

Annotation Cluster 32: Enrichment Score: 2.16

nucleocytoplasmic transport

nuclear transport

intracellular transport

domain:Importin N-terminal

nuclear import

Importin-beta, $\mathrm{N}$-terminal

Armadillo-like helical

protein import into nucleus, docking

protein import into nucleus

protein localization in nucleus

nuclear pore

protein transporter activity

pore complex

nuclear envelope

protein import

intracellular protein transport

protein localization in organelle

cellular protein localization

cellular macromolecule localization

endomembrane system

protein targeting

protein localization

protein transport

protein transport

establishment of protein localization

Annotation Cluster 33: Enrichment Score: 1.85

posttranscriptional regulation of gene expression
3.10E-02

1.70E-01

5.30E-01

$5.50 \mathrm{E}-01$

$5.80 \mathrm{E}-02$

$5.50 \mathrm{E}-01$

$6.80 \mathrm{E}-01$

$9.50 \mathrm{E}-02$

P Value

1.20E-03

$1.80 \mathrm{E}-03$

$3.70 \mathrm{E}-03$

$5.10 \mathrm{E}-03$

$1.10 \mathrm{E}-02$

$1.60 \mathrm{E}-02$

$7.80 \mathrm{E}-02$

$P$ Value

2.80E-06

$3.30 \mathrm{E}-06$

$3.90 \mathrm{E}-04$

$6.70 \mathrm{E}-04$

$7.80 \mathrm{E}-04$

$1.20 \mathrm{E}-03$

$2.60 \mathrm{E}-03$

$2.80 \mathrm{E}-03$

$3.60 \mathrm{E}-03$

$5.50 \mathrm{E}-03$

$1.00 \mathrm{E}-02$

$1.80 \mathrm{E}-02$

$2.20 \mathrm{E}-02$

$2.20 \mathrm{E}-02$

$2.50 \mathrm{E}-02$

$2.80 \mathrm{E}-02$

$4.00 \mathrm{E}-02$

$5.10 \mathrm{E}-02$

$5.30 \mathrm{E}-02$

$6.60 \mathrm{E}-02$

$7.70 \mathrm{E}-02$

$7.90 \mathrm{E}-02$

9.00E-02

$1.00 \mathrm{E}-01$

1.10E-01

P_Value

$1.00 \mathrm{E}-03$
Benjamini

3.10E-02

$4.20 \mathrm{E}-02$

$7.30 \mathrm{E}-02$

$9.10 \mathrm{E}-02$

5.40E-02

$6.90 \mathrm{E}-02$

$5.30 \mathrm{E}-01$

Benjamini

2.50E-04

$2.50 \mathrm{E}-04$

$1.40 \mathrm{E}-02$

$2.80 \mathrm{E}-02$

$2.20 \mathrm{E}-02$

$3.00 \mathrm{E}-02$

$5.50 \mathrm{E}-02$

$6.00 \mathrm{E}-02$

$7.20 \mathrm{E}-02$

$9.60 \mathrm{E}-02$

8.00E-02

2.10E-01

$1.30 \mathrm{E}-01$

$1.30 \mathrm{E}-01$

$2.80 \mathrm{E}-01$

$3.00 \mathrm{E}-01$

$3.70 \mathrm{E}-01$

4.20E-01

4.30E-01

3.00E-01

$5.30 \mathrm{E}-01$

$5.30 \mathrm{E}-01$

3.00E-01

$6.00 \mathrm{E}-01$

$6.20 \mathrm{E}-01$

Benjamini

2.80E-02 
translation regulation

regulation of translation

Annotation Cluster 35: Enrichment Score: 1.88

coenzyme metabolic process

cellular amide metabolic process

cofactor metabolic process

nicotinamide metabolic process

nicotinamide nucleotide metabolic process

alkaloid metabolic process

pyridine nucleotide metabolic process

oxidoreduction coenzyme metabolic process

NAD metabolic process

secondary metabolic process

Annotation Cluster 35: Enrichment Score: 1.85

maintenance of location

cytoskeletal anchoring at plasma membrane

maintenance of location in cell

maintenance of protein location in cell

maintenance of protein location

Annotation Cluster 36: Enrichment Score: 1.83

redox-active disulfide

Redox-active center

cell redox homeostasis

Mercuric reductase

Pyridine nucleotide-disulphide oxidoreductase, class

I, active site

Pyridine nucleotide-disulphide oxidoreductase, dimerisation

Pyridine nucleotide-disulphide oxidoreductase,

NAD-binding region

oxidoreductase activity, acting on sulfur group of donors, NAD or NADP as acceptor

FAD-dependent pyridine nucleotide-disulphide oxidoreductase

nucleotide phosphate-binding region:FAD

Flavoprotein

Thioredoxin fold

FAD binding

oxidoreductase activity, acting on sulfur group of donors

FAD
Count

11

7

11

4

4

4

4

4

3

4

Count

6

3

5

4

4

\section{Count}

4

6

7

3

3

3

3

3
$1.00 \mathrm{E}-02$

$2.10 \mathrm{E}-01$

$P$ Value

3.10E-04

$3.80 \mathrm{E}-04$

$2.00 \mathrm{E}-03$

$3.10 \mathrm{E}-02$

$3.10 \mathrm{E}-02$

$3.30 \mathrm{E}-02$

$3.50 \mathrm{E}-02$

$6.00 \mathrm{E}-02$

$6.80 \mathrm{E}-02$

$1.50 \mathrm{E}-01$

$P$ Value

4.80E-03

$7.70 \mathrm{E}-03$

9.10E-03

$3.30 \mathrm{E}-02$

$4.90 \mathrm{E}-02$

P_Value

1.10E-04

$1.80 \mathrm{E}-04$

$7.20 \mathrm{E}-04$

$2.00 \mathrm{E}-03$

$2.00 \mathrm{E}-03$

5.50E-03

7.00E-03

1.00E-02

3.00E-02

$4.30 \mathrm{E}-02$

4.70E-02

$5.90 \mathrm{E}-02$

$1.30 \mathrm{E}-01$

1.50E-01

$1.80 \mathrm{E}-01$
5.10E-02

$8.00 \mathrm{E}-01$

Benjamini

1.20E-02

$1.40 \mathrm{E}-02$

4.50E-02

$3.10 \mathrm{E}-01$

3.10E-01

3. $20 \mathrm{E}-01$

3.40E-01

4.50E-01

4.90E-01

7.10E-01

Benjamini

9.00E-02

$1.20 \mathrm{E}-01$

$1.40 \mathrm{E}-01$

3.20E-01

4.10E-01

Benjamini

1.10E-03

$1.60 \mathrm{E}-03$

$2.10 \mathrm{E}-02$

4.50E-02

4.50E-02

$1.00 \mathrm{E}-01$

$1.30 \mathrm{E}-01$

1.30E-01

3.60E-01

$5.60 \mathrm{E}-01$

$1.80 \mathrm{E}-01$

$5.50 \mathrm{E}-01$

$6.90 \mathrm{E}-01$

7.30E-01

$5.00 \mathrm{E}-01$ 
oxidoreductase activity, acting on NADH or NADPH 3

electron carrier activity

Annotation Cluster 37: Enrichment Score: 1.82

Heat shock protein 70

Heat shock protein Hsp70

PIRSF002581:chaperone HSP70

Heat shock protein 70, conserved site

Antigen processing and presentation

Annotation Cluster 38: Enrichment Score: 1.75

ATP-grasp fold, subdomain 2

ligase

ligase activity, forming carbon-nitrogen bonds

Annotation Cluster 39: Enrichment Score: 1.65

multifunctional enzyme

purine biosynthesis

ligase activity, forming carbon-nitrogen bonds

Annotation Cluster 40: Enrichment Score: 1.59

MLL5-L complex

methyltransferase complex

histone methyltransferase complex

Annotation Cluster 41: Enrichment Score: 1.58

organelle localization

establishment of organelle localization

establishment of vesicle localization

vesicle localization

Annotation Cluster 42: Enrichment Score: 1.51

actin capping

cell cortex part

actin filament capping

negative regulation of actin filament depolymerization

cortical cytoskeleton

spectrin

repeat:Spectrin 10

repeat:Spectrin 11

repeat:Spectrin 12

repeat:Spectrin 13
$5.40 \mathrm{E}-01$

$9.80 \mathrm{E}-01$

Count

3

3

3

3

7

Count

4

11

5

Count

6

3

5

Count

3

3

3

Count
7
6
3
3

Count

4

7

4

4

5

3

3

3

3

3
P Value

5.00E-03

$6.60 \mathrm{E}-03$

$1.10 \mathrm{E}-01$

$1.30 \mathrm{E}-01$

P Value

1.30E-02

1.30E-02

$1.30 \mathrm{E}-02$

$1.90 \mathrm{E}-02$

$2.00 \mathrm{E}-02$

P_Value

$1.80 \mathrm{E}-03$

$5.70 \mathrm{E}-03$

$5.80 \mathrm{E}-01$

P_Value

2.00E-03

9.70E-03

$5.80 \mathrm{E}-01$

P_Value

7.30E-03

$4.80 \mathrm{E}-02$

$4.80 \mathrm{E}-02$

$1.30 \mathrm{E}-0$

P_Value

$1.70 \mathrm{E}-03$

$2.70 \mathrm{E}-03$

$6.00 \mathrm{E}-03$

7.70E-03

$9.00 \mathrm{E}-03$

$9.30 \mathrm{E}-03$

$9.80 \mathrm{E}-03$

$9.80 \mathrm{E}-03$

$9.80 \mathrm{E}-03$

$9.80 \mathrm{E}-03$
Benjamini

1.90E-01

$1.90 \mathrm{E}-01$

2.20E-01

$2.60 \mathrm{E}-01$

$2.10 \mathrm{E}-01$

Benjamini

4.00E-02

$3.20 \mathrm{E}-02$

9.90E-01

Benjamini

1.30E-02

$4.80 \mathrm{E}-02$

9.90E-01

Benjamini

6.30E-02

2.30E-01

$2.30 \mathrm{E}-01$

Benjamini

9.20E-02

$1.10 \mathrm{E}-01$

6.10E-01

$6.60 \mathrm{E}-01$

Benjamini

1.10E-02

$2.80 \mathrm{E}-02$

$1.00 \mathrm{E}-01$

1.20E-01

7.50E-02

7.30E-02

$2.20 \mathrm{E}-01$

$2.20 \mathrm{E}-01$

$2.20 \mathrm{E}-01$

$2.20 \mathrm{E}-01$ 


\begin{tabular}{|c|c|c|c|}
\hline repeat:Spectrin 14 & 3 & $9.80 \mathrm{E}-03$ & $2.20 \mathrm{E}-01$ \\
\hline repeat:Spectrin 15 & 3 & $9.80 \mathrm{E}-03$ & $2.20 \mathrm{E}-01$ \\
\hline repeat:Spectrin 16 & 3 & $9.80 \mathrm{E}-03$ & $2.20 \mathrm{E}-01$ \\
\hline repeat:Spectrin 17 & 3 & $9.80 \mathrm{E}-03$ & $2.20 \mathrm{E}-01$ \\
\hline regulation of actin filament depolymerization & 4 & $1.10 \mathrm{E}-02$ & $1.60 \mathrm{E}-01$ \\
\hline repeat:Spectrin 7 & 3 & $1.20 \mathrm{E}-02$ & $2.50 \mathrm{E}-01$ \\
\hline repeat:Spectrin 6 & 3 & $1.20 \mathrm{E}-02$ & $2.50 \mathrm{E}-01$ \\
\hline repeat:Spectrin 9 & 3 & $1.20 \mathrm{E}-02$ & $2.50 \mathrm{E}-01$ \\
\hline repeat:Spectrin 8 & 3 & $1.20 \mathrm{E}-02$ & $2.50 \mathrm{E}-01$ \\
\hline negative regulation of actin filament polymerization & 4 & $1.20 \mathrm{E}-02$ & $1.70 \mathrm{E}-01$ \\
\hline negative regulation of protein polymerization & 4 & $1.30 \mathrm{E}-02$ & $1.70 \mathrm{E}-01$ \\
\hline negative regulation of organelle organization & 6 & $1.30 \mathrm{E}-02$ & $1.70 \mathrm{E}-01$ \\
\hline repeat:Spectrin 5 & 3 & $1.30 \mathrm{E}-02$ & $2.70 \mathrm{E}-01$ \\
\hline actin cytoskeleton & 11 & $1.50 \mathrm{E}-02$ & $1.10 \mathrm{E}-01$ \\
\hline negative regulation of protein complex assembly & 4 & $2.00 \mathrm{E}-02$ & $2.30 \mathrm{E}-01$ \\
\hline repeat:Spectrin 4 & 3 & $2.90 \mathrm{E}-02$ & 4.50E-01 \\
\hline repeat:Spectrin 3 & 3 & $3.20 \mathrm{E}-02$ & 4.70E-01 \\
\hline negative regulation of protein complex disassembly & 4 & $3.30 \mathrm{E}-02$ & $3.20 \mathrm{E}-01$ \\
\hline Spectrin repeat & 3 & 3.70E-02 & 4.10E-01 \\
\hline repeat:Spectrin 1 & 3 & 4.30E-02 & $5.50 \mathrm{E}-01$ \\
\hline repeat:Spectrin 2 & 3 & 4.30E-02 & $5.50 \mathrm{E}-01$ \\
\hline SPEC & 3 & 4.80E-02 & 4.00E-01 \\
\hline regulation of protein complex disassembly & 4 & $5.70 \mathrm{E}-02$ & 4.40E-01 \\
\hline regulation of actin filament polymerization & 4 & $6.50 \mathrm{E}-02$ & 4.80E-01 \\
\hline negative regulation of cytoskeleton organization & 4 & $6.80 \mathrm{E}-02$ & 4.90E-01 \\
\hline regulation of protein complex assembly & 5 & $6.90 \mathrm{E}-02$ & 4.90E-01 \\
\hline Spectrin/alpha-actinin & 3 & 7.40E-02 & $6.10 \mathrm{E}-01$ \\
\hline cortical actin cytoskeleton & 3 & 7.90E-02 & $3.40 \mathrm{E}-01$ \\
\hline regulation of organelle organization & 8 & $8.00 \mathrm{E}-02$ & $5.30 \mathrm{E}-01$ \\
\hline regulation of cytoskeleton organization & 6 & $8.50 \mathrm{E}-02$ & $5.50 \mathrm{E}-01$ \\
\hline $\begin{array}{l}\text { regulation of actin polymerization or depolymeriza- } \\
\text { ion }\end{array}$ & 4 & 8.70E-02 & $5.50 \mathrm{E}-01$ \\
\hline regulation of actin filament length & 4 & $9.40 \mathrm{E}-02$ & $5.70 \mathrm{E}-01$ \\
\hline actin-binding & 7 & $9.50 \mathrm{E}-02$ & $3.10 \mathrm{E}-01$ \\
\hline $\begin{array}{l}\text { negative regulation of cellular component organiza- } \\
\text { ion }\end{array}$ & 6 & $9.80 \mathrm{E}-02$ & $5.80 \mathrm{E}-01$ \\
\hline regulation of protein polymerization & 4 & $1.10 \mathrm{E}-01$ & $6.20 \mathrm{E}-01$ \\
\hline regulation of actin cytoskeleton organization & 4 & $2.00 \mathrm{E}-01$ & 7.80E-01 \\
\hline regulation of actin filament-based process & 4 & $2.10 \mathrm{E}-01$ & $8.00 \mathrm{E}-01$ \\
\hline actin binding & 9 & 2.10E-01 & $8.30 \mathrm{E}-01$ \\
\hline regulation of cellular component biogenesis & 5 & $2.30 \mathrm{E}-01$ & $8.20 \mathrm{E}-01$ \\
\hline regulation of cellular component size & 7 & $3.20 \mathrm{E}-01$ & $9.00 \mathrm{E}-01$ \\
\hline cytoskeletal protein binding & 11 & $3.90 \mathrm{E}-01$ & $9.50 \mathrm{E}-01$ \\
\hline
\end{tabular}


Annotation Cluster 43: Enrichment Score: 1.47

Count

P_Value

Benjamini

identical protein binding

3.50E-04

7.40E-03

protein homodimerization activity

$2.30 \mathrm{E}-01$

$8.50 \mathrm{E}-01$

protein dimerization activity

$4.80 \mathrm{E}-01$

$9.70 \mathrm{E}-01$

Annotation Cluster 44: Enrichment Score: 1.45

Count

P_Value

Benjamini

Heat shock protein Hsp90, conserved site

PIRSF002583:heat shock protein, HSP90/HTPG

.00E-03

4.50E-02 types

9.90E-03

1.90E-01

Heat shock protein Hsp90

$1.30 \mathrm{E}-02$

$1.90 \mathrm{E}-01$

HATPase_c

$4.50 \mathrm{E}-02$

$4.30 \mathrm{E}-01$

ATP-binding region, ATPase-like

$7.00 \mathrm{E}-02$

$5.90 \mathrm{E}-01$

Prostate cancer

NOD-like receptor signaling pathway

$2.00 \mathrm{E}-01$

$6.70 \mathrm{E}-01$

Annotation Cluster 45: Enrichment Score: 1.43

Count

P_Value

Benjamini

magnesium

4.40E-03

2.60E-02

metal ion-binding site:Magnesium

$1.70 \mathrm{E}-02$

$3.10 \mathrm{E}-01$

magnesium ion binding

$2.80 \mathrm{E}-02$

$2.80 \mathrm{E}-01$

metal-binding

$9.00 \mathrm{E}-01$

$1.00 \mathrm{E}+00$

Annotation Cluster 46: Enrichment Score: 1.41

Count

$P$ Value

Benjamini

multifunctional enzyme

2.00E-03

1.30E-02

ribonucleotide metabolic process

$1.30 \mathrm{E}-02$

$1.70 \mathrm{E}-01$

ribonucleotide biosynthetic process

$2.00 \mathrm{E}-02$

$2.30 \mathrm{E}-01$

nucleobase biosynthetic process

$2.30 \mathrm{E}-02$

$2.60 \mathrm{E}-01$

ribonucleoside monophosphate biosynthetic process

$5.90 \mathrm{E}-02$

4.50E-01

nucleobase metabolic process

$5.90 \mathrm{E}-02$

4.50E-01

ribonucleoside monophosphate metabolic process

$6.80 \mathrm{E}-02$

$4.90 \mathrm{E}-01$

nucleoside monophosphate biosynthetic process

nucleoside monophosphate metabolic process

$2.10 \mathrm{E}-01$

$8.00 \mathrm{E}-01$

$3.10 \mathrm{E}-01$

$8.90 \mathrm{E}-01$

Annotation Cluster 47: Enrichment Score: 1.39

Count
3
3
3
3
3
Count
3

$P$ Value

Benjamini

domain:KH 3

$1.30 \mathrm{E}-02$

$2.70 \mathrm{E}-01$

domain:KH 1

3.40E-02

4.90E-01

domain:KH 2

$3.40 \mathrm{E}-02$

4.90E-01

K Homology, type 1

8.20E-02

$6.30 \mathrm{E}-01$

K Homology, type 1, subgroup

9.10E-02

6.70E-01

Annotation Cluster 48: Enrichment Score: 1.31

26S proteasome subunit $\mathrm{P} 45$

P_Value

Benjamini

4.20E-03

8.10E-02 
Posttranslational modification, protein turnover, chaperones

negative regulation of ubiquitin-protein ligase activity during mitotic cell cycle

anaphase-promoting complex-dependent proteasomal ubiquitin-dependent protein catabolic process negative regulation of ubiquitin-protein ligase activity

regulation of ubiquitin-protein ligase activity during mitotic cell cycle

7.40E-03

$1.20 \mathrm{E}-01$

proteasomal protein catabolic process

$8.20 \mathrm{E}-03$

$1.20 \mathrm{E}-01$

proteasomal ubiquitin-dependent protein catabolic process

8.20E-03

$1.20 \mathrm{E}-01$

negative regulation of protein ubiquitination

$8.80 \mathrm{E}-03$

$1.30 \mathrm{E}-01$

regulation of ubiquitin-protein ligase activity

$1.10 \mathrm{E}-02$

$1.60 \mathrm{E}-01$

negative regulation of cellular protein metabolic process

regulation of ligase activity

$1.30 \mathrm{E}-02$

$1.70 \mathrm{E}-01$

ATPase, AAA-type, conserved site

$1.30 \mathrm{E}-02$

$1.70 \mathrm{E}-01$

negative regulation of protein metabolic process

$1.30 \mathrm{E}-02$

$1.90 \mathrm{E}-01$

negative regulation of protein modification process

$1.50 \mathrm{E}-02$

$1.90 \mathrm{E}-01$

proteasome complex

$1.70 \mathrm{E}-02$

$2.00 \mathrm{E}-01$

regulation of protein ubiquitination

$1.90 \mathrm{E}-02$

$1.30 \mathrm{E}-01$

positive regulation of ubiquitin-protein ligase activity

$2.90 \mathrm{E}-02$

3.00E-01

during mitotic cell cycle

2.90E-02

3.00E-01

positive regulation of ubiquitin-protein ligase activity

$3.20 \mathrm{E}-02$

3.20E-01

Proteasome

$3.30 \mathrm{E}-02$

$2.70 \mathrm{E}-01$

regulation of cellular protein metabolic process

$3.50 \mathrm{E}-02$

$3.40 \mathrm{E}-01$

positive regulation of ligase activity

$3.70 \mathrm{E}-02$

$3.50 \mathrm{E}-01$

positive regulation of protein ubiquitination

$5.60 \mathrm{E}-02$

$4.40 \mathrm{E}-01$

macromolecule catabolic process

$7.90 \mathrm{E}-02$

$5.30 \mathrm{E}-01$

ubiquitin-dependent protein catabolic process

$1.20 \mathrm{E}-01$

$6.50 \mathrm{E}-01$

cellular macromolecule catabolic process

$1.80 \mathrm{E}-01$

$7.60 \mathrm{E}-01$

positive regulation of catalytic activity

$1.80 \mathrm{E}-01$

$7.60 \mathrm{E}-01$

negative regulation of molecular function

$2.20 \mathrm{E}-01$

$8.00 \mathrm{E}-01$

regulation of protein modification process

$2.40 \mathrm{E}-01$

$8.30 \mathrm{E}-01$

positive regulation of molecular function

$3.10 \mathrm{E}-01$

$8.90 \mathrm{E}-01$

negative regulation of catalytic activity

3.40E-01

$9.10 \mathrm{E}-01$

positive regulation of cellular protein metabolic process

modification-dependent macromolecule catabolic process 


\begin{tabular}{|c|c|c|c|}
\hline positive regulation of protein modification process & 5 & $4.00 \mathrm{E}-01$ & $9.40 \mathrm{E}-01$ \\
\hline positive regulation of protein metabolic process & 6 & $4.00 \mathrm{E}-01$ & $9.40 \mathrm{E}-01$ \\
\hline $\begin{array}{l}\text { proteolysis involved in cellular protein catabolic pro- } \\
\text { cess }\end{array}$ & 12 & $4.60 \mathrm{E}-01$ & $9.60 \mathrm{E}-01$ \\
\hline cellular protein catabolic process & 12 & 4.60E-01 & $9.60 \mathrm{E}-01$ \\
\hline protein catabolic process & 12 & $5.00 \mathrm{E}-01$ & $9.70 \mathrm{E}-01$ \\
\hline proteolysis & 17 & 7.30E-01 & $1.00 \mathrm{E}+00$ \\
\hline $\begin{array}{l}\text { positive regulation of macromolecule metabolic pro- } \\
\text { cess }\end{array}$ & 8 & $9.90 \mathrm{E}-01$ & $1.00 \mathrm{E}+00$ \\
\hline Annotation Cluster 49: Enrichment Score: 1.3 & Count & $\mathrm{P}_{-}$Value & Benjamini \\
\hline domain:Actin-binding & 3 & $2.70 \mathrm{E}-02$ & 4.30E-01 \\
\hline Actinin-type, actin-binding, conserved site & 3 & 4.30E-02 & 4.60E-01 \\
\hline $\mathrm{CH}$ & 4 & $4.50 \mathrm{E}-02$ & $4.80 \mathrm{E}-01$ \\
\hline domain:CH 1 & 3 & 4.60E-02 & $5.70 \mathrm{E}-01$ \\
\hline domain:CH 2 & 3 & $4.60 \mathrm{E}-02$ & $5.70 \mathrm{E}-01$ \\
\hline Calponin-like actin-binding & 4 & $8.10 \mathrm{E}-02$ & $6.40 \mathrm{E}-01$ \\
\hline actin-binding & 7 & $9.50 \mathrm{E}-02$ & $3.10 \mathrm{E}-01$ \\
\hline Annotation Cluster 50: Enrichment Score: 1.29 & Count & $\mathrm{P}_{-}$Value & Benjamini \\
\hline pyridoxal phosphate & 5 & $7.90 \mathrm{E}-03$ & 4.20E-02 \\
\hline vitamin B6 binding & 4 & $6.80 \mathrm{E}-02$ & $5.00 \mathrm{E}-01$ \\
\hline pyridoxal phosphate binding & 4 & $6.80 \mathrm{E}-02$ & $5.00 \mathrm{E}-01$ \\
\hline vitamin binding & 5 & $1.90 \mathrm{E}-01$ & $8.10 \mathrm{E}-01$ \\
\hline Annotation Cluster 51: Enrichment Score: 1.27 & Count & $\mathrm{P}_{-}$Value & Benjamini \\
\hline cellular amino acid biosynthetic process & 5 & $1.10 \mathrm{E}-02$ & $1.60 \mathrm{E}-01$ \\
\hline amino-acid biosynthesis & 3 & $3.70 \mathrm{E}-02$ & $1.40 \mathrm{E}-01$ \\
\hline amine biosynthetic process & 5 & $5.00 \mathrm{E}-02$ & 4.20E-01 \\
\hline glutamine family amino acid metabolic process & 4 & $6.00 \mathrm{E}-02$ & $4.50 \mathrm{E}-01$ \\
\hline aspartate family amino acid metabolic process & 3 & $6.30 \mathrm{E}-02$ & 4.70E-01 \\
\hline carboxylic acid biosynthetic process & 6 & $1.30 \mathrm{E}-01$ & $6.60 \mathrm{E}-01$ \\
\hline organic acid biosynthetic process & 6 & $1.30 \mathrm{E}-01$ & $6.60 \mathrm{E}-01$ \\
\hline Annotation Cluster 52: Enrichment Score: 1.27 & Count & P_Value & Benjamini \\
\hline purine nucleotide metabolic process & 10 & $4.80 \mathrm{E}-03$ & $9.00 \mathrm{E}-02$ \\
\hline ribonucleotide metabolic process & 8 & $1.30 \mathrm{E}-02$ & $1.70 \mathrm{E}-01$ \\
\hline purine nucleotide catabolic process & 4 & $1.90 \mathrm{E}-02$ & $2.20 \mathrm{E}-01$ \\
\hline ATP catabolic process & 3 & $3.00 \mathrm{E}-02$ & $3.10 \mathrm{E}-01$ \\
\hline purine ribonucleotide metabolic process & 7 & $3.20 \mathrm{E}-02$ & $3.20 \mathrm{E}-01$ \\
\hline purine ribonucleoside triphosphate catabolic process & 3 & 4.10E-02 & $3.80 \mathrm{E}-01$ \\
\hline ribonucleoside triphosphate catabolic process & 3 & 4.10E-02 & $3.80 \mathrm{E}-01$ \\
\hline heterocycle catabolic process & 5 & 4.30E-02 & $3.90 \mathrm{E}-01$ \\
\hline
\end{tabular}




\begin{tabular}{|c|c|c|c|}
\hline purine nucleoside triphosphate catabolic process & 3 & $5.00 \mathrm{E}-02$ & 4.20E-01 \\
\hline nucleotide catabolic process & 4 & 5.70E-02 & 4.40E-01 \\
\hline purine ribonucleotide catabolic process & 3 & 5.90E-02 & 4.50E-01 \\
\hline nucleoside triphosphate catabolic process & 3 & $6.30 \mathrm{E}-02$ & 4.70E-01 \\
\hline ribonucleotide catabolic process & 3 & $6.80 \mathrm{E}-02$ & 4.90E-01 \\
\hline $\begin{array}{l}\text { nucleobase, nucleoside and nucleotide catabolic pro- } \\
\text { cess }\end{array}$ & 4 & 7.70E-02 & $5.30 \mathrm{E}-01$ \\
\hline $\begin{array}{l}\text { nucleobase, nucleoside, nucleotide and nucleic acid } \\
\text { catabolic process }\end{array}$ & 4 & 7.70E-02 & $5.30 \mathrm{E}-01$ \\
\hline ATP metabolic process & 5 & $1.10 \mathrm{E}-01$ & $6.00 \mathrm{E}-01$ \\
\hline nitrogen compound catabolic process & 4 & $1.10 \mathrm{E}-01$ & $6.10 \mathrm{E}-01$ \\
\hline purine ribonucleoside triphosphate metabolic process & 5 & $1.40 \mathrm{E}-01$ & $6.90 \mathrm{E}-01$ \\
\hline ribonucleoside triphosphate metabolic process & 5 & $1.40 \mathrm{E}-01$ & $6.90 \mathrm{E}-01$ \\
\hline purine nucleoside triphosphate metabolic process & 5 & $1.60 \mathrm{E}-01$ & 7.20E-01 \\
\hline nucleoside triphosphate metabolic process & 5 & $1.90 \mathrm{E}-01$ & 7.70E-01 \\
\hline Annotation Cluster 53: Enrichment Score: 1.26 & Count & $\mathrm{P}_{-}$Value & Benjamini \\
\hline nadp & 7 & $1.50 \mathrm{E}-02$ & $6.70 \mathrm{E}-02$ \\
\hline binding site:NADP & 3 & 4.90E-02 & $5.90 \mathrm{E}-01$ \\
\hline nucleotide phosphate-binding region:NADP & 3 & 2.30E-01 & $9.80 \mathrm{E}-01$ \\
\hline Annotation Cluster 54: Enrichment Score: 1.26 & Count & $\mathrm{P}_{-}$Value & Benjamini \\
\hline Actin, conserved site & 3 & 2.20E-02 & $2.80 \mathrm{E}-01$ \\
\hline PIRSF002337:Actin & 3 & $5.50 \mathrm{E}-02$ & $6.10 \mathrm{E}-01$ \\
\hline ACTIN & 3 & 7.20E-02 & 4.50E-01 \\
\hline Actin/actin-like & 3 & $1.10 \mathrm{E}-01$ & 7.20E-01 \\
\hline Annotation Cluster 55: Enrichment Score: 1.17 & Count & P_Value & Benjamini \\
\hline repeat:HEAT 1 & 4 & $3.80 \mathrm{E}-02$ & $5.20 \mathrm{E}-01$ \\
\hline repeat:HEAT 2 & 4 & $3.80 \mathrm{E}-02$ & $5.20 \mathrm{E}-01$ \\
\hline repeat:HEAT 4 & 3 & $1.00 \mathrm{E}-01$ & 8.40E-01 \\
\hline repeat:HEAT 3 & 3 & $1.30 \mathrm{E}-01$ & $9.00 \mathrm{E}-01$ \\
\hline Annotation Cluster 56: Enrichment Score: 1.12 & Count & P_Value & Benjamini \\
\hline regulation of cell cycle & 13 & $1.20 \mathrm{E}-02$ & $1.60 \mathrm{E}-01$ \\
\hline regulation of cell cycle process & 5 & $1.30 \mathrm{E}-01$ & $6.60 \mathrm{E}-01$ \\
\hline regulation of mitotic cell cycle & 5 & $2.60 \mathrm{E}-01$ & $8.50 \mathrm{E}-01$ \\
\hline Annotation Cluster 57: Enrichment Score: 1.12 & Count & P_Value & Benjamini \\
\hline metal ion-binding site:Potassium & 3 & $2.40 \mathrm{E}-03$ & $7.60 \mathrm{E}-02$ \\
\hline metal ion-binding site:Magnesium & 6 & $1.70 \mathrm{E}-02$ & $3.10 \mathrm{E}-01$ \\
\hline potassium & 4 & $2.20 \mathrm{E}-01$ & $5.50 \mathrm{E}-01$ \\
\hline potassium ion binding & 4 & $3.90 \mathrm{E}-01$ & $9.50 \mathrm{E}-01$ \\
\hline
\end{tabular}


Annotation Cluster 58: Enrichment Score: 1.05

Count

short sequence motif:Prevents secretion from ER

P_Value

Benjamini

Endoplasmic reticulum, targeting sequence

$1.00 \mathrm{E}-04$

5.30E-03

endoplasmic reticulum lumen

$4.60 \mathrm{E}-04$

$1.50 \mathrm{E}-02$

cellular homeostasis

$2.20 \mathrm{E}-03$

$2.60 \mathrm{E}-02$

endoplasmic reticulum part

$1.80 \mathrm{E}-01$

$7.50 \mathrm{E}-01$

endoplasmic reticulum

$2.30 \mathrm{E}-01$

$6.60 \mathrm{E}-01$

endoplasmic reticulum

$6.90 \mathrm{E}-01$

$9.60 \mathrm{E}-01$

disulfide bond

9.30E-01

$1.00 \mathrm{E}+00$

disulfide bond

$1.00 \mathrm{E}+00$

$1.00 \mathrm{E}+00$

signal

$1.00 \mathrm{E}+00$

$1.00 \mathrm{E}+00$

signal peptide

$1.00 \mathrm{E}+00$

$1.00 \mathrm{E}+00$

11

$1.00 \mathrm{E}+00$

$1.00 \mathrm{E}+00$

Annotation Cluster 59: Enrichment Score: 1.03

nitrogen compound biosynthetic process

Count

$\mathrm{P}$ Value

Benjamini

nucleotide biosynthetic process

4.90E-04

1.70E-02

nucleobase, nucleoside, nucleotide and nucleic acid biosynthetic process

$1.40 \mathrm{E}-03$

$3.60 \mathrm{E}-02$

nucleobase, nucleoside and nucleotide biosynthetic process

1.80E-03

4.40E-02

purine nucleotide metabolic process

$1.80 \mathrm{E}-03$

4.40E-02

ribonucleotide metabolic process

purine nucleotide biosynthetic process

$4.80 \mathrm{E}-03$

$9.00 \mathrm{E}-02$

$1.30 \mathrm{E}-02$

$1.70 \mathrm{E}-01$

ribonucleotide biosynthetic process

$1.40 \mathrm{E}-02$

$1.70 \mathrm{E}-01$

purine ribonucleotide metabolic process

$2.00 \mathrm{E}-02$

2.30E-01

purine ribonucleotide biosynthetic process

$3.20 \mathrm{E}-02$

3.20E-01

ATP metabolic process

$5.10 \mathrm{E}-02$

$4.20 \mathrm{E}-01$

$1.10 \mathrm{E}-01$

$6.00 \mathrm{E}-01$

ATPase activity, coupled to transmembrane movement of substances

1.20E-01

$7.00 \mathrm{E}-01$

ATPase activity, coupled to movement of substances

$1.30 \mathrm{E}-01$

$7.10 \mathrm{E}-01$

hydrolase activity, acting on acid anhydrides, catalyzing transmembrane movement of substances

$1.30 \mathrm{E}-01$

$7.00 \mathrm{E}-01$

cation-transporting ATPase activity

$1.30 \mathrm{E}-01$

$7.00 \mathrm{E}-01$

ATPase activity, coupled to transmembrane movement of ions

$1.40 \mathrm{E}-01$

7.10E-01

purine ribonucleoside triphosphate metabolic process

$1.40 \mathrm{E}-01$

$6.90 \mathrm{E}-01$

ribonucleoside triphosphate metabolic process

$1.40 \mathrm{E}-01$

$6.90 \mathrm{E}-01$

purine nucleoside triphosphate metabolic process

$1.60 \mathrm{E}-01$

7.20E-01

primary active transmembrane transporter activity

$1.70 \mathrm{E}-01$

7.70E-01

P-P-bond-hydrolysis-driven transmembrane transporter activity

$1.70 \mathrm{E}-01$

7.70E-01

nucleoside triphosphate metabolic process

$1.90 \mathrm{E}-01$

7.70E-01 
ATP biosynthetic process

purine ribonucleoside triphosphate biosynthetic process

ATPase activity, coupled to transmembrane movement of ions, phosphorylative mechanism

ribonucleoside triphosphate biosynthetic process

purine nucleoside triphosphate biosynthetic process

nucleoside triphosphate biosynthetic process

inorganic cation transmembrane transporter activity

monovalent inorganic cation transmembrane transporter activity

Alzheimer's disease

monovalent inorganic cation transport

ion transport

cation transport

metal ion transport

ion transport

Annotation Cluster 60: Enrichment Score: 1.01

Integrin Signaling Pathway

Erk1/Erk2 Mapk Signaling pathway

Signaling of Hepatocyte Growth Factor Receptor
2.40E-01

$8.50 \mathrm{E}-01$

$2.40 \mathrm{E}-01$

$8.30 \mathrm{E}-01$

$2.40 \mathrm{E}-01$

$8.30 \mathrm{E}-01$

$2.50 \mathrm{E}-01$

$8.40 \mathrm{E}-01$

4.90E-01

9.80E-01

3

$5.50 \mathrm{E}-01$

9.80E-01

6.20E-01

$9.20 \mathrm{E}-01$

3

9.70E-01

$1.00 \mathrm{E}+00$

9.80E-01

$1.00 \mathrm{E}+00$

9.90E-01

$1.00 \mathrm{E}+00$

$1.00 \mathrm{E}+00$

$1.00 \mathrm{E}+00$

5

$1.00 \mathrm{E}+00$

$1.00 \mathrm{E}+00$

$\begin{array}{lll}\text { Count } & \text { P_Value } & \text { Benjamini } \\ 5 & 3.20 \mathrm{E}-02 & 8.70 \mathrm{E}-01 \\ 4 & 8.40 \mathrm{E}-02 & 8.00 \mathrm{E}-01 \\ 3 & 3.50 \mathrm{E}-01 & 9.80 \mathrm{E}-01\end{array}$

Supplemental Table 3. The list of KEGG pathways obtained by DAVID software analysis based on the list of proteins shown in Supplemental Table 1: a partial list of proteins from HeLa cell forming corona on dopamine coated nanoparticles.

$\begin{array}{llll}\text { KEGG_PATHWAY Term } & \text { Count } & \text { p Value } & \text { Benjamini } \\ \text { hsa00020:Citrate cycle (TCA cycle) } & 15 & 0.000 & 0.000 \\ \text { hsa03030:DNA replication } & 14 & 0.000 & 0.000 \\ \text { hsa03040:Spliceosome } & 24 & 0.000 & 0.000 \\ \text { hsa05130:Pathogenic Escherichia coli infection } & 15 & 0.000 & 0.000 \\ \text { hsa03430: Mismatch repair } & 9 & 0.000 & 0.000 \\ \text { hsa00970:Aminoacyl-tRNA biosynthesis } & 11 & 0.000 & 0.000 \\ \text { hsa00010:Glycolysis / Gluconeogenesis } & 13 & 0.000 & 0.000 \\ \text { hsa00630:Glyoxylate and dicarboxylate metabolism } & 7 & 0.000 & 0.001 \\ \text { hsa00620:Pyruvate metabolism } & 10 & 0.000 & 0.002 \\ \text { hsa03050:Proteasome } & 9 & 0.002 & 0.025 \\ \text { hsa04540:Gap junction } & 12 & 0.004 & 0.048 \\ \text { hsa00640:Propanoate metabolism } & 7 & 0.004 & 0.047 \\ \text { hsa00280:Valine, leucine and isoleucine degradation } & 8 & 0.005 & 0.054 \\ \text { hsa03420:Nucleotide excision repair } & 8 & 0.005 & 0.054 \\ \text { hsa00270:Cysteine and methionine metabolism } & 7 & 0.005 & 0.055\end{array}$


Supplemental Table 4. The list of Annotation Clusters obtained by DAVID software analysis based on the list of mRNAs found to be differentially expressed in nanoparticle treated cells. Two clusters with enrichment scores above 1 are presented.

Annotation cluster 1: Enrichment Score: 1.85

HLH

domain:Helix-loop-helix motif

Basic helix-loop-helix dimerisation region bHLH

71.Id_proteins_G0-to-S_cell_cycle

TGF-beta signaling pathway

negative regulation of molecular function

negative regulation of transcription factor activity

negative regulation of DNA binding

response to organic substance

negative regulation of binding

negative regulation of transcription from RNA polymerase

II promoter

regulation of transcription factor activity

response to protein stimulus

regulation of DNA binding

negative regulation of transcription, DNA-dependent

negative regulation of RNA metabolic process

negative regulation of macromolecule metabolic process

regulation of binding

negative regulation of transcription

negative regulation of gene expression

negative regulation of nucleobase, nucleoside, nucleotide

and nucleic acid metabolic process

negative regulation of nitrogen compound metabolic process

heart development

transcription repressor activity

negative regulation of macromolecule biosynthetic process

negative regulation of cellular biosynthetic process

negative regulation of biosynthetic process

developmental protein

transcription regulator activity

regulation of cell cycle

regulation of transcription from RNA polymerase II pro-

moter

nucleus

regulation of transcription, DNA-dependent

regulation of RNA metabolic process

$\begin{array}{lll}\text { Count } & \text { P_Value } & \text { Benjamini } \\ 4 & 1.50 \mathrm{E}-04 & 1.50 \mathrm{E}-03 \\ 4 & 2.50 \mathrm{E}-04 & 2.00 \mathrm{E}-02 \\ 4 & 3.30 \mathrm{E}-04 & 1.50 \mathrm{E}-02 \\ 3 & 4.70 \mathrm{E}-04 & 2.30 \mathrm{E}-03 \\ 4 & 9.50 \mathrm{E}-04 & 1.30 \mathrm{E}-02 \\ 5 & 1.30 \mathrm{E}-03 & 3.20 \mathrm{E}-01 \\ 3 & 2.00 \mathrm{E}-03 & 2.50 \mathrm{E}-01 \\ 3 & 2.50 \mathrm{E}-03 & 2.20 \mathrm{E}-01 \\ 6 & 3.40 \mathrm{E}-03 & 2.20 \mathrm{E}-01 \\ 3 & 3.40 \mathrm{E}-03 & 1.80 \mathrm{E}-01 \\ 4 & 6.70 \mathrm{E}-03 & 2.20 \mathrm{E}-01 \\ 3 & 1.00 \mathrm{E}-02 & 2.80 \mathrm{E}-01 \\ 3 & 1.10 \mathrm{E}-02 & 2.70 \mathrm{E}-01 \\ 3 & 1.40 \mathrm{E}-02 & 3.10 \mathrm{E}-01 \\ 4 & 1.50 \mathrm{E}-02 & 3.10 \mathrm{E}-01 \\ 4 & 1.50 \mathrm{E}-02 & 3.00 \mathrm{E}-01 \\ 5 & 2.10 \mathrm{E}-02 & 3.20 \mathrm{E}-01 \\ 3 & 2.10 \mathrm{E}-02 & 3.10 \mathrm{E}-01 \\ 4 & 2.90 \mathrm{E}-02 & 3.80 \mathrm{E}-01 \\ 4 & 3.70 \mathrm{E}-02 & 4.40 \mathrm{E}-01 \\ 4 & 3.80 \mathrm{E}-02 & 4.30 \mathrm{E}-01 \\ 4 & 3.90 \mathrm{E}-02 & 4.30 \mathrm{E}-01 \\ 3 & 4.00 \mathrm{E}-02 & 4.20 \mathrm{E}-01 \\ 3 & 4.40 \mathrm{E}-02 & 9.60 \mathrm{E}-01 \\ 4 & 4.50 \mathrm{E}-02 & 4.40 \mathrm{E}-01 \\ 4 & 4.80 \mathrm{E}-02 & 4.50 \mathrm{E}-01 \\ 4 & 5.00 \mathrm{E}-02 & 4.60 \mathrm{E}-01 \\ 4 & 5.10 \mathrm{E}-02 & 9.60 \mathrm{E}-01 \\ 5 & 7.10 \mathrm{E}-02 & 9.30 \mathrm{E}-01 \\ 3 & 8.50 \mathrm{E}-02 & 6.10 \mathrm{E}-01 \\ 4 & 8.90 \mathrm{E}-02 & 5.90 \mathrm{E}-01 \\ 8 & 1.70 \mathrm{E}-01 & 9.40 \mathrm{E}-01 \\ 5 & 2.60 \mathrm{E}-01 & 9.20 \mathrm{E}-01 \\ 5 & 2.80 \mathrm{E}-01 & 9.20 \mathrm{E}-01\end{array}$


Annotation cluster 2: Enrichment Score: 1.16

$\begin{array}{lll}\text { Count } & \text { P_Value } & \text { Benjamini } \\ 4 & 5.70 \mathrm{E}-02 & 4.80 \mathrm{E}-01 \\ 4 & 5.90 \mathrm{E}-02 & 4.80 \mathrm{E}-01 \\ 3 & 6.40 \mathrm{E}-02 & 8.70 \mathrm{E}-01 \\ 4 & 8.70 \mathrm{E}-02 & 6.00 \mathrm{E}-01 \\ 4 & 8.80 \mathrm{E}-02 & 6.00 \mathrm{E}-01\end{array}$

apoptosis

programmed cell death

Apoptosis

cell death

$8.80 \mathrm{E}-02$

$6.00 \mathrm{E}-01$

\section{Supplemental references}

[1] T. Rajh, L. X. Chen, K. Lukas, T. Liu, M. C. Thurnauer, and D. M. Tiede, "Surface Restructuring of Nanoparticles: An Efficient Route for Ligand-Metal Oxide Crosstalk," The Journal of Physical Chemistry B, vol. 106, no. 41, pp. 10543-10552, 2002/10/01 2002.

[2] R. Bazak et al., "Cytotoxicity and DNA cleavage with core-shell nanocomposites functionalized by a KH domain DNA binding peptide," Nanoscale, vol. 5, no. 23, pp. 11394-9, Dec 72013.

[3] E. M. B. Brown et al., "Methods for assessing DNA hybridization of peptide nucleic acid-titanium dioxide nanoconjugates," (in English), Analytical Biochemistry, vol. 383, no. 2, pp. 226-235, Dec 152008.

[4] P. J. Endres, T. Paunesku, S. Vogt, T. J. Meade, and G. E. Woloschak, "DNA-TiO2 nanoconjugates labeled with magnetic resonance contrast agents," (in English), Journal of the American Chemical Society, vol. 129, no. 51, pp. 15760-+, Dec 262007.

[5] T. Paunesku et al., "Gadolinium-conjugated TiO2-DNA oligonucleotide nanoconjugates show prolonged intracellular retention period and T1-weighted contrast enhancement in magnetic resonance images," (in eng), Nanomedicine, vol. 4, no. 3, pp. 201-7, Sep 2008.

[6] T. Paunesku et al., "Biology of TiO2-oligonucleotide nanocomposites," (in eng), Nat Mater, vol. 2, no. 5, pp. 343-6, May 2003.

[7] T. Paunesku et al., "Intracellular distribution of TiO2-DNA oligonucleotide nanoconjugates directed to nucleolus and mitochondria indicates sequence specificity," (in eng), Nano Lett, vol. 7, no. 3, pp. 596601, Mar 2007.

[8] K. T. Thurn et al., "Endocytosis of titanium dioxide nanoparticles in prostate cancer PC-3M cells," Nanomedicine, vol. 7, no. 2, pp. 123-30, Apr 2011.

[9] K. T. Thurn et al., "Labeling TiO2 nanoparticles with dyes for optical fluorescence microscopy and determination of TiO2-DNA nanoconjugate stability," (in eng), Small, vol. 5, no. 11, pp. 1318-25, Jun 2009.

[10] A. G. Wu et al., "Titanium dioxide nanoparticles assembled by DNA molecules hybridization and loading of DNA interacting proteins," (in English), Nano, vol. 3, no. 1, pp. 27-36, Feb 2008.

[11] Y. Yuan et al., "Epidermal growth factor receptor targeted nuclear delivery and high-resolution whole cell X-ray imaging of Fe3O4@TiO2 nanoparticles in cancer cells," (in eng), ACS Nano, vol. 7, no. 12, pp. 10502-17, Dec 232013.

[12] H. C. Arora et al., "Nanocarriers enhance Doxorubicin uptake in drug-resistant ovarian cancer cells," (in eng), Cancer Res, vol. 72, no. 3, pp. 769-78, Feb 012012.

[13] A. Michelmore, W. Q. Gong, P. Jenkins, and J. Ralston, "The interaction of linear polyphosphates with titanium dioxide surfaces," (in English), Physical Chemistry Chemical Physics, Article vol. 2, no. 13, pp. 2985-2992, 2000. 